\title{
Cryptosporidium spp. and Giardia duodenalis emissions from humans and animals in the Three Gorges Reservoir in Chongqing, China
}

\author{
Qian Huang ${ }^{1}$, Ling Yang ${ }^{1}$, Bo Li ${ }^{1}$, Huihui Du ${ }^{1,2}{ }^{2}$ Feng Zhao ${ }^{1}$, Lin Han ${ }^{1,2}{ }^{\text {, }}$ Qilong Wang ${ }^{1}$, Yunjia Deng ${ }^{1}$, Guosheng \\ Xiao \\ Dayong Wang ${ }^{4}$ \\ 1 \\ of Biology and Food Engineering, Chongqing Three Gorges University, Wanzhou, Chongqing, China \\ 2 Engineering Technology Research Center of Characteristic Biological Resources in Northeast Chongqing, Chongqing Three Gorges University, Wanzhou, \\ Chongqing, China \\ 3 Key Laboratory of Water Environment Evolution and Pollution Control in Three Gorges Reservoir, Chongqing Three Gorges University, Wanzhou, \\ Chongqing, China \\ 4 Medical School, Southeast University, Nanjing, Jiangsu, China \\ Corresponding Author: Guosheng Xiao \\ Email address: xgs03@sanxiau.edu.cn
}

Cryptosporidium spp. and Giardia duodenalis are two waterborne protozoan parasites that can cause diarrhea. Human and animal feces in surface water are a major source of these pathogens. This paper presents a GloWPa-TGR-Crypto model that estimates

Cryptosporidium and G. duodenalis emissions from human and animal feces in the Three Gorges Reservoir (TGR), and uses scenario analysis to predict the effects of sanitation, urbanization, and population growth on oocyst and cyst emissions for 2050. Our model estimated annual emissions of $1.6 \times 10^{15}$ oocysts and $2.1 \times 10^{15}$ cysts from human and animal feces, respectively. Humans were the largest contributors of oocysts and cysts, followed by pigs and poultry. Cities were hot-spots for human emissions, while districts with high livestock populations accounted for the highest animal emissions. Our model was the most sensitive to oocyst excretion rates. The results indicated that $74 \%$ and $87 \%$ of total emissions came from urban areas and humans, respectively, and $86 \%$ of total human emissions were produced by the urban population. The scenario analysis showed a potential decrease in oocyst and cyst emissions with improvements in urbanization, sanitation, wastewater treatment, and manure management, regardless of population increase. Our model can further contribute to the understanding of environmental pathways, the risk assessment of Cryptosporidium and Giardia pollution, and effective prevention and control strategies that can reduce the outbreak of waterborne diseases in the TGR and other similar watersheds. 


\section{Cryptosporidium spp. and Giardia duodenalis}

2 emissions from humans and animals in the Three

3 Gorges Reservoir in Chongqing, China

4

5

6

7

8

9

10

11

30

31

32

33

34

35

36

37

38

39

40

Qian Huang ${ }^{1}$, Ling Yang ${ }^{1}$, Bo Li ${ }^{1}$, Huihui $\mathrm{Du}^{1,2}$, Feng Zhao ${ }^{1}$, Lin Han ${ }^{1,2}$, Qilong Wang ${ }^{1}$, Yunjia Deng $^{1}$, Guosheng Xiao ${ }^{1,2,3}$, and Dayong Wang ${ }^{4}$

${ }^{1}$ College of Biology and Food Engineering, Chongqing Three Gorges University, Wanzhou, Chongqing, China

${ }^{2}$ Engineering Technology Research Center of Characteristic Biological Resources in Northeast Chongqing, Chongqing Three Gorges University, Wanzhou, Chongqing, China

${ }^{3}$ Key Laboratory of Water Environment Evolution and Pollution Control in Three Gorges

Reservoir, Chongqing Three Gorges University, Wanzhou, Chongqing, China

${ }^{4}$ Medical School, Southeast University, Nanjing, Jiangsu, China

Corresponding Author:

Guosheng Xiao

College of Biology and Food and Engineering, Chongqing Three Gorges University, Wanzhou District, Chongqing, China

Email address: xgs03@sanxiau.edu.cn 


\section{Abstract}

42 Cryptosporidium spp. and Giardia duodenalis are two waterborne protozoan parasites that can

43 cause diarrhea. Human and animal feces in surface water are a major source of these pathogens.

44 This paper presents a GloWPa-TGR-Crypto model that estimates Cryptosporidium and G.

45 duodenalis emissions from human and animal feces in the Three Gorges Reservoir (TGR), and

46 uses scenario analysis to predict the effects of sanitation, urbanization, and population growth on

47 oocyst and cyst emissions for 2050 . Our model estimated annual emissions of $1.6 \times 10^{15}$ oocysts

48 and $2.1 \times 10^{15}$ cysts from human and animal feces, respectively. Humans were the largest

49 contributors of oocysts and cysts, followed by pigs and poultry. Cities were hot-spots for human

50 emissions, while districts with high livestock populations accounted for the highest animal

51 emissions. Our model was the most sensitive to oocyst excretion rates. The results indicated that

$5274 \%$ and $87 \%$ of total emissions came from urban areas and humans, respectively, and $86 \%$ of

53 total human emissions were produced by the urban population. The scenario analysis showed a

54 potential decrease in oocyst and cyst emissions with improvements in urbanization, sanitation,

55 wastewater treatment, and manure management, regardless of population increase. Our model

56 can further contribute to the understanding of environmental pathways, the risk assessment of

57 Cryptosporidium and Giardia pollution, and effective prevention and control strategies that can reduce the outbreak of waterborne diseases in the TGR and other similar watersheds.

59

60

61

62

63

64

65

66

67

68

69

70

71

72

\section{Introduction}

Cryptosporidium spp. and Giardia duodenalis are two ubiquitous parasites that can cause gastrointestinal disease in humans and many animals worldwide (Šlapeta, 2013; Ryan, Fayer, \& Xiao, 2014; Wu et al., 2018; Sahraoui et al., 2019). They can cause cryptosporidiosis and giardiasis, which are typically self-limiting infections in immunocompetent individuals, but are life-threatening illnesses in immunocompromised people, such as AIDS patients (Xiao \& Fayer, 2008; Liu et al., 2016; Ghafari et al., 2018 ). In developing countries, diarrhea has been identified as the third leading cause of death (WHO, 2008), and global deaths from diarrhea are around 1.3 million annually $(G B D, 2015)$. There are also many waterborne cryptosporidiosis and giardiasis outbreaks regularly reported in developed countries (Hoxie et al., 1997; Bartelt, Attias, \& Black, 2016).

Humans and many animals are important reservoirs for Cryptosporidium spp. and $G$. duodenalis, and large amounts of both pathogens and extremely high oocyst and cyst excretions have been traced in their feces (Graczyk \& Fried, 2007; Tangtrongsup et al., 2019). Moreover, the transmission of these parasites occurs through a variety of mechanisms in the fecal-oral route, including the direct contact with or indirect ingestion of contaminated food or water (Castro-Hermida et al., 2009; Dixon \& Brent, 2016; Saaed \& Ongerth, 2019). These parasites can enter and pollute surface water directly through sewage sludge or indirectly through field runoff (Graczyk et al., 2008; Mons et al., 2008). Oocysts and cycsts are highly infectious, very stable in environmental water, and largely resistant to many chemical and physical inactivation agents (Carmena et al., 2007; Castro-Hermida, Gonzalez-Warleta, \& Mezo, 2015; Adeyemo et 
81 al., 2019), making the presence of waterborne Cryptosporidium spp. and G. duodenalis 82 pathogens in surface water a serious public health threat (Wu et al., 2018; Li et al., 2019).

83 Cryptosporidiosis and giardiasis have been reported in at least 300 areas and more than 90 84 countries worldwide (Yang et al., 2017). Previous studies have predicted that Cryptosporidium is 85 in $4 \%$ to $31 \%$ of the stools of immunocompetent people living in developing countries (Quihui86 Cota et al., 2017) and in 1\% of the stools of people with high incomes (Checkley et al., 2015). 87 Additionally, it has been estimated that more than 200 million people are chronically infected 88 with giardiasis, with 500,000 new cases reported each year, and that waterborne Giardia 89 outbreaks affect approximately $10 \%$ of the world's population (Norhayati et al., 2003; Saaed \& 90 Ongerth, 2019). To date, Cryptosporidium spp. and G. duodenalis have been found in more than 9127 provincial administrative regions in China (Yang et al., 2017; Liu et al., 2020). However, 92 there continues to be a critical lack of surveillance systems documenting and tracking protozoan infection and waterborne outbreaks in developing countries (Baldursson \& Karanis, 2011; Efstratiou, Ongerth, \& Karanis, 2017ab). Cryptosporidium and Giardia have recently been added as pathogens in China's Standards for Drinking Water Quality (GB/T5749-2006, 2007), suggesting that greater attention is being paid to waterborne parasite control in a region with no previous monitoring and reporting systems. Nevertheless, the incidence rate and risks of waterborne protozoan illness are still poorly understood in China, making it difficult to combat parasitic protozoa, manage source water, and assess future risks (An et al., 2012; Xiao et al., 2013a; Baldursson \& Karanis, 2011).

The Three Gorges Reservoir (TGR), one of the world's largest comprehensive hydropower projects, is located at the upper reaches of the Yangtze River, the longest river in Asia (He et al., 2011; Sang et al., 2019). It is an important source of water and plays a crucial role in China's economy (Li, Huang, \& $Q u, 2017)$ by optimizing their water resources. Serious pollution from agricultural activities and domestic sewage discharge have adversely affected the sustainable development of the TGR and the entire Yangtze River Basin, and pose a threat to future resources (Fu et al., 2010; Yang et al., 2015). There is a lack of observational data on Cryptosporidium and Giardia emissions from people and livestock in China. The existing data does show that monitoring programs are expensive, time-consuming, and often cannot detect or properly measure the ambient concentrations of oocysts and cysts (Efstratiou, Ongerth \& Karanis, 2017ab; Martins et al., 2019). Understanding the environmental emissions and transmission routes of parasitic protozoa is beneficial when developing strategies to assess and mitigate waterborne diseases. In this study, we aimed to: (i) use a spatially explicit model to estimate total annual oocyst and cyst emissions from human and livestock feces in the TGR; (ii) use scenario analysis to explore the impacts of population growth, urbanization, and sanitation changes on human and animal Cryptosporidium and Giardia emissions in surface water; and (iii) contribute to a general understanding of the risk of protozoan parasites and to strategies that will control and reduce the burden of waterborne pathogens in the TGR.

\section{Materials \& Methods}




\section{Study area and model components}

122 The TGR Area is located at $28^{\circ} 30^{\prime}$ to $31^{\circ} 44^{\prime} \mathrm{N}$ and $105^{\circ} 44^{\prime}$ to $111^{\circ} 39^{\prime} \mathrm{E}$ in the lower section of

123 the upper reaches of the Yangtze River. It has a watershed of $46,118 \mathrm{~km}^{2}$, reaches approximately

12416.8 million residents, and its river system covers 38 Chongqing districts and counties (Fig. 1).

125 Using the area's population (Fig.1A) and livestock density (Fig.1B) (Table S1), we applied the

126 GloWPa-TGR-Crypto model to estimate oocyst and cyst emissions in the Chongqing region of

127 the TGR (Hofstra et al., 2013). We defined an emission as the annual total number of oocysts

128 and cysts excreted by people and livestock found in surface water. We used the emission data

129 from 2013 for our model since the records for human and livestock populations from that year

130 were the most complete. The model (GloWPa-TGR-Crypto) consisted of two components: a

131 human emission model and an animal emission model. Figure 2 shows a schematic sketch of the

132 model's components. We identified the two types of pollution sources for the total oocysts and

133 cysts found in the TGR. Point sources were human emissions connected to sewage systems that

134 indirectly reached the TGR after treatment, or directly before treatment. Nonpoint sources were

135 emissions from rural residents or livestock resulting from manure being used as fertilizer and

136 entering surface water via runoff. Our model was partly based on Hofstra et al. (2013) and other

137 reviews suggesting improvements in manure treatment of livestock and human emissions

138 (Hofstra et al., 2013; Vermeulen et al., 2015; Vermeulen et al., 2017). We ran the model at both

139 district and county levels. Our model can't differentiate Cryptosporidium species, as there was

140 the paucity of the prevalence and excretion rates for different species in humans and livestock.

141

142 Calculating oocyst and cyst excretion in human feces $(\boldsymbol{H})$

143 Using population $(P)$, sanitation availability $(F)$, and excretion $\left(O_{p}\right)$ data from 2013 , the model

144 first estimated human oocyst and cyst emissions. We divided the human populations into four

145 emission categories: connected sources, direct sources, diffuse sources, and non-sources. The

146 detailed descriptions of the emission categories are provided in Kiulia et al. (2015). The model

147 not only calculated the human emissions connected to sewers in urban and rural areas, but it also

148 calculated direct and diffuse emissions. Unlike Kiulia et al. (2015), our model did not

149 differentiate across age categories. In rural areas of China, a portion of fecal waste is collected

150 and used for fertilizer and irrigation. Therefore, we assumed that human feces runoff from septic

151 tanks and pit latrines was a diffuse source of oocysts and cysts in surface water. The two

152 protozoan parasites' prevalence rate was 10\% in developing countries (Human Development

153 Index (HDI) < 0.785; Hofstra et al., 2013), and the average excretion rate $\left(O_{p}\right)$ was assumed to

154 be $1.0 \times 10^{8}$ and $1.58 \times 10^{8}$ for oocysts and cysts, respectively (Ferguson et al., 2007; Hofstra

155 et al., 2013). Our model used the secondary sewage treatment according to the Chinese discharge

156 standard of pollutants for municipal wastewater treatment plants (GB18918-2002) and the

157 Chinese technological policy for the treatment of municipal sewage and pollution control

158 (http://www.mee.gov.cn/). The removal efficiencies were 10\%, 50\%, and $95 \%$, for primary,

159 secondary, and tertiary treatments, respectively (Hofstra et al., 2013). The results $(H)$ were

160 calculated using Eq. (1) and (2): 
$161 K_{i} \in\left\{K_{1}, K_{2}, K_{3}, K_{4}\right\}, \mathrm{i} \in\{1,2,3,4\}$, representing four state sets.

$162 K_{1}---$ Urban connected emissions

$163 K_{2}$---Rural connected emissions

$164 K_{3}^{---U r b a n ~ d i r e c t ~ e m i s s i o n s ~}$

$165 K_{4}-$--Rural diffuse emissions

166 Oocyst and cyst excretions $\left(K_{i}\right)$ from each human emission (i) per district were calculated as

167 follows:

168

$$
\text { st. }\left\{\begin{array}{l}
K_{1}=C E_{u}=P_{u} \times F_{c u} \times O_{p} \times\left(1-F_{r e m}\right) \\
K_{2}=C E_{r}=P_{r} \times F_{c r} \times O_{p} \times\left(1-F_{r e m}\right) \\
K_{3}=D E_{u}=P_{u} \times F_{d u} \times O_{p} \\
K_{4}=D i f E_{r}=P_{r} \times F_{\text {difr }} \times O_{p}
\end{array}\right.
$$

169

$$
H=\sum_{i=1}^{4} K_{i}
$$

170

171

172

173

174

175

176

177

178

179

180

181

182

183

184

185

186

187

188

189

where $H$ is the total oocyst and cyst excretion from different human emission categories in a district or county (oocysts and cycsts/year); $P_{u}$ and $P_{r}$ are total urban and rural populations in districts or counties, respectively; $O_{p}$ is the average oocyst and cyst excretion rates per person per year (oocysts and cysts/year); $F_{c u}$ and $F_{c r}$ are the fractions of urban and rural populations connected to a sewer, respectively; $F_{d u}$ is the fraction of urban populations not connected to a sewer that is considered a direct source; $F_{d i f r}$ is the fraction of rural populations not using sanitation that is considered a diffuse source; and $F_{r e m}$ is the fraction of oocysts and cysts removed by sewage treatment plants (STP). The values assumed for this study are summarized in Tables S1 and S2.

\section{Calculating oocyst and cyst excretion in animal manure $(A)$}

Using the number of livestock, breeding day, manure excretion, oocyst and cyst excretion rate, and prevalence rate, the model then estimated livestock oocyst and cyst emissions in 2013 . We established six livestock categories: rabbits, pigs, cattle, poultry, sheep, and goats. Unlike Hofstra et al. (2013), our model used different livestock breeding day categories because each livestock species has a unique number of breeding days before slaughter and produces different amounts of manure and excretions each year. We also divided the animal populations into four emission categories: (1) connected emissions from livestock receiving manure treatment, (2) direct emissions from livestock directly discharged to surface water, (3) diffuse emissions resulting from using livestock manure as a fertilizer after storage, and (4) livestock manure that 
190 was not used for irrigation after storage or for any other use (e.g., burned for fuel) (Vermeulen et 191 al., 2015; Vermeulen et al., 2017). We assumed that 10\% of emissions would be connected 192 emissions (Zhang et al., 2017). Illegal and undocumented direct emissions (e.g., dumped manure) 193 were not included in our model due to a lack of data. The results $(A)$ were calculated using Eq.

194 (3) and (4):

$195 X_{j} \in\left\{X_{1}, X_{2}, X_{3}, X_{4}, X_{5}\right\}, \mathrm{j} \in\{1,2,3,4,5\}$

$196 X_{1}$---Rabbit emissions

$197 X_{2}---$ Pig emissions

$198 X_{3}$---Cattle emissions

$199 X_{4}$---Sheep and goat emissions

$200 X_{5}$---Poultry emissions

201 We calculated oocyst and cyst excretions $\left(X_{j}\right)$ from each animal species $(j)$ per district using the 202 following equation:

$$
\begin{gathered}
X_{j}=N_{a_{j}} \times D_{a_{j}} \times M_{a_{j}} \times O_{a_{j}} \times P_{a_{j}} \\
A=\sum_{j=1}^{5} X_{j}
\end{gathered}
$$

203

204

205

206

207

208

209

210

211

212

213

214

215

216

217

218

219

where $X_{j}$ is the oocyst and cyst excretions from livestock species $\mathrm{j}$ in a district or county (oocysts and cysts/year), $N_{a_{j}}$ is the number of animals in a district or county, $D_{a_{j}}$ is the breeding day for different livestock species $\mathrm{j}$ (days), $M_{a_{j}}$ is the mean daily manure of livestock species $\mathrm{j}\left(\mathrm{kg} \cdot \mathrm{day}^{-}\right.$ $\left.{ }^{1}\right), O_{a_{j}}$ is the oocyst and cyst excretion rate per infected livestock species $\mathrm{j}$ in manure $\left({ }^{10} \log \right.$ (oo)cysts $\cdot \mathrm{kg}^{-1} \cdot \mathrm{d}^{-1}$ ), and $P_{a_{j}}$ is the prevalence of cryptosporidiosis and giardiasis in livestock species j. The values assumed for this study are summarized in Tables S1, S3, S4, and S5.

\section{Calculating oocyst and cyst emissions after manure storage (S)}

In China, manure from human diffuse and livestock sources is collected and used for irrigation and fertilizer (Liu et al., 2019). The decay of oocysts and cysts in manure that has been stored before being applied as fertilizer in the TGR watershed is temperature-dependent during the storage period (Tang et al., 2011; Vermeulen et al., 2017). The number of oocysts and cysts in stored manure that has been loaded on land during irrigation was calculated using Eq. (5):

$$
S=\text { DifE }_{r} \times F_{s, h} \times F_{v}+A \times F_{s, a} \times F_{v}
$$

where $S$ is the number of oocysts and cysts in manure that has been spread on land after storage in a district or county (oocysts and cysts/year); Dif $E_{r}$ and $A$ are the number of oocysts and cysts in manure for rural residents (human diffuse sources) and livestock (oocysts and cysts/year), respectively; $F_{s, h}$ and $F_{s, a}$ are the proportions of stored manure applied as a fertilizer from rural 
220 residents and livestock, respectively (Table S2); and $F_{v}$ is the proportion of average oocyst and 221 cyst survival in the storage system.

222 The average oocyst and cyst survival rate $\left(F_{v}\right)$ in the storage system depended on 223 temperature $(T)$ and storage time $\left(t_{s}\right)$ (Vermeulen et al., 2017). The results were calculated using 224 Eq. (6), (7), and (8):

$$
\begin{gathered}
K_{s}=\frac{\ln 10}{-2.5586 \times T+119.63} \\
V_{s,}=e^{\left(-K_{s} \times t_{s}\right)} \\
F_{v}=\frac{\int_{0}^{t_{s}} V_{s} d t}{t_{s}}
\end{gathered}
$$

225

226

227

228

229

230

231

232

233

234

235

236

237

238

239

240

241

242

243

244

245

246

247

where $T$ is the average annual air temperature $\left({ }^{\circ} \mathrm{C}\right)$ (Table $\left.\mathrm{S} 2\right), K_{s}$ is a constant based on air temperature, $V_{s}$ is the survival rate of oocysts and cysts over time, and $t_{s}$ is the manure storage time (days) (Table S2).

\section{Calculating oocyst and cyst runoff $(R)$ to the TGR}

Oocysts and cysts in stored manure that have been applied to agricultural land as a fertilizer are transported from land to rivers largely via surface runoff (Velthof et al., 2009). Our model estimated oocyst and cyst runoff using the amounts of manure applied as fertilizer, maximal surface runoff, and a set of reduction factors (Velthof et al., 2009; Hofstra et al., 2013). The results $(R)$ were calculated using Eq. (9):

$$
R=S \times F_{\text {run, } \max } \times f_{l u} \times f_{p} \times f_{r c} \times f_{s}
$$

where $R$ is the number of oocysts and cysts in manure applied as a fertilizer that reached the TGR via surface runoff in a district or county (oocysts and cysts/year), $S$ is the number of oocysts and cysts in manure that was spread on land after storage (oocyst and cysts/year), $F_{r u n, \max }$ is the fraction of maximum surface runoff across different slope classes, $f_{l u}$ is the reduction factor for land use, $f_{p}$ is the reduction factor for average annual precipitation, $f_{r c}$ is the reduction factor for rock depth, and $f_{s}$ is the reduction factor for soil type. The values assumed for this study are summarized in Table S2.

\section{Calculating total emissions $(E)$ and mean concentrations $(C)$ of oocysts and cysts}

Our model defined total oocyst and cyst emissions as the annual number of oocysts and cysts per district in the TGR. The results $(E)$ were calculated using Eq. (10):

$$
E=C E_{u}+C E_{r}+D E_{u}+R
$$

where $E$ is the total oocyst and cyst emissions from humans and animals in a district or county (oocysts and cysts/year), $C E_{u}$ is oocyst and cyst emissions in the TGR by urban populations 
248

250

251

252

253

254

255

256

257

258

259

260

261

262

263

264

265

266

267

268

269

270

271

272

273

274

275

276

277

278

279

280

281

282

283

284

connected to STP in a district or county, $C E_{r}$ is oocyst and cyst emissions in the TGR by rural populations connected to STP in a district or county, $D E_{u}$ is direct oocyst and cyst emissions in the TGR by urban populations in a district or county, and $R$ is oocyst and cyst emissions in the TGR from human and livestock manure that has been applied as a fertilizer via runoff in a district or county.

According to total emissions from the two protozoa in Chongqing and the TGR's hydrological information, we preliminarily calculated mean Cryptosporidium and Giardia concentrations in the TGR in 2013 using the GloWPa-Crypto C1 model (Vermeulen et al., 2019). Mean concentrations were calculated using Eq. (11). All equations and parameters used in this study were showed in Table S11.

$$
C=\frac{E_{t} \times e^{-\left(K_{T}+K_{R}+K_{S}\right) \times t}}{Q_{s}}
$$

Where $C$ is mean concentrations of oocysts and cysts (oocysts and cysts $\cdot 10 \mathrm{~L}^{-1}$ ), $E_{t}$ is the sum of total oocyst and cyst emissions from humans and animals in all districts or counties in Chongqing (oocysts and cysts/year). $K_{T}, K_{R}$, and $K_{S}$ represent loss rate constants of temperature, solar radiation, and sedimentation, respectively $\left(\right.$ day $\left.^{-1}\right) \cdot t$ is residence time of oocysts and cysts in Chongqing section of the TGR, $Q_{s}$ is the sum of the TGR's annual inflow and storage capacity $\left(\mathrm{m}^{3} \cdot\right.$ year $\left.^{-1}\right)$.

\section{Sensitivity analysis}

We tested our model's sensitivity to change using input parameters in a nominal range sensitivity analysis (NRSA). Input parameter values were based on reasonable lower and upper ranges of a base model, and we tested each variable individually (Vermeulen et al., 2015; Vermeulen et al., 2017). We selected the NRSA because it provides quantitative insight into the individual impact of different parameters on the model's outcome. Tables S6, S7, and S8 present the sensitivity analysis input variables.

\section{Predicting total oocyst and cyst emissions for $\mathbf{2 0 5 0}$}

To explore the impact of future population, urbanization, and sanitation changes on human and animal Cryptosporidium and Giardia emissions in the TGR, we divided the emissions into urban resident, rural resident, and livestock categories to predict the total oocyst and cyst emissions for 2050 based on three scenarios. China's projected population, urbanization, and livestock production data for 2050 can be found in the Shared Socioeconomic Pathways (SSPs) database (Zhao, 2018; Huang et al., 2019; Chen et al., 2020) (https://ntcat.iiasa.ac.at/SspDb). We based Scenario 1 on SSP1, which is entitled "Sustainability - Taking the green road" and emphasizes sustainability, well-being, and equity. In this scenario, there is moderate population change and well-planned urbanization (O'Neill, Kriegle, \& Ebi, 2015; Jiang \& O'Neill, 2017; Zhao, 2018; Huang et al., 2019; Chen et al., 2020). Scenario 2 was based on SSP3, which is entitled "Regional rivalry - A rocky road" and emphasizes regional progress. In this scenario, China's 
285

286

287

288

289

290

291

292

293

294

295

296

297

298

299

300

301

302

303

304

305

306

307

308

309

310

311

312

313

314

315

316

317

318

319

320

321

322

323

324

population change is significant and urbanization is unplanned ( $O^{\prime} N e i l l$, Kriegle, \& Ebi, 2015; Jiang \& O'Neill, 2017; Zhao, 2018; Huang et al., 2019; Chen et al., 2020). To emphasize the importance of wastewater and manure treatment, we created Scenario 3 as a variation of Scenario 1 based on Hofstra \& Vermeulen (2016). This scenario has the same population, urbanization, and sanitation changes as Scenario 1, but with the insufficient sewage and manure treatments from 2013. Since there were no available data for individual livestock species, we assumed that all livestock species will grow by the same percentage noted in the SSPs database. We also assumed that there will be changes only in population and livestock numbers, not in any other parameters (e.g., oocyst and cyst excretion rates and prevalence) (Iqbal, Islam, \& Hofstra, 2019). We based our sanitation, wastewater, and manure treatment predictions for these three scenarios on previous literature reviews (Hofstra \& Vermeulen, 2016; Iqbal, Islam, \& Hofstra, 2019). Table S9 provides an overview of the scenarios.

\section{Results}

\section{Emissions and mean concentrations of oocysts and cysts in the TGR in 2013}

Cryptosporidium oocyst and Giardia cyst emissions from humans, rabbits, pigs, cattle, sheep, goats, and poultry found in the TGR in 2013 are shown in Figure 3. Chongqing had a total of $1.6 \times 10^{15}$ oocysts/year and $2.1 \times 10^{15}$ cysts/year of Cryptosporidium and Giardia emissions. Human Cryptosporidium and Giardia emissions contained a total of $1.2 \times 10^{15}$ oocysts/year and $2.0 \times 10^{15}$ cysts/year, and animal emissions had a total of $3.4 \times 10^{14}$ oocysts/year and $1.5 \times 10^{14}$ cysts/year. Humans and animals were responsible for $42 \%$ and $10 \%$ of total emissions in the TGR, respectively. Humans were responsible for $78 \%$ of oocyst emissions, followed by $14 \%$ from pigs, and $8 \%$ from poultry. Humans were responsible for $93 \%$ of cyst emissions, followed by $6 \%$ from pigs, and $0.5 \%$ from cattle. Ultimately, we found that humans were the dominant source of oocysts and cysts, followed by pigs, poultry, and cattle. The mean Cryptosporidium and Giardia concentrations in the TGR in 2013 were 22 oocysts/10 L and 28 cysts/10 L, respectively.

\section{Oocyst and cyst emission sanitation types}

We immediately observed the differences in sanitation types (connected emissions, direct emissions, diffuse emissions, and non-source) across the human, livestock, urban, and rural populations (Fig. 4). We found that $49 \%$ of the populations were connected to a sewer, $36 \%$ had diffuse sources, $13 \%$ had direct sources, and $2 \%$ were non-source. In livestock populations, only $10 \%$ were connected to a sewer (manure treatment), $80 \%$ produced diffuse emissions, and $10 \%$ were non-source. We divided the human and livestock emissions by region: urban areas (made up of urban residents) and rural areas (made up of rural residents and all livestock). In urban areas, the emissions connected to a sewer were prominent (78\%), followed by direct sources (22\%). In rural areas, diffuse sources produced approximately $85 \%$ of total emissions, followed by connected sources $(9 \%)$, and non-source $(6 \%)$. 
325 Spatial distribution of oocyst and cyst emissions in the TGR in 2013

326 Our model produced a spatial distribution of Cryptosporidium and Giardia emissions in the TGR 327 for each Chongqing district or county from 2013 (Fig. 5). The total human Cryptosporidium 328 emissions ranged from $5.4 \times 10^{12}$ to $7.4 \times 10^{13}$ oocysts/district (Fig. $5 \mathrm{~A}$ ) and the total human 329 Giardia emissions ranged from $8.5 \times 10^{12}$ to $1.2 \times 10^{14} \mathrm{cysts} /$ district (Fig. 5B). Overall, the 330 emission spatial differences depended on population density and urbanization rate. The largest emissions were from the densely-populated Yubei, Wanzhou, and Jiulongpo districts.

The total animal source emissions ranged from 0 to $1.8 \times 10^{13}$ oocysts/district (Fig. $5 \mathrm{C}$ ) and 0 to $7.2 \times 10^{13}$ cysts/district (Fig. 5D) for Cryptosporidium and Giardia, respectively. We based our

335

336 results on the number of animals, manure production, manure treatment and runoff, and invariant oocyst and cyst emissions from each animal category over one year. The lowest emissions were

337 observed in areas with low animal populations, such as the downtown districts of Yuzhong, Dadukou, and Nanan.

339

The total Cryptosporidium and Giardia emissions ranged from $1.0 \times 10^{13}$ to $8.1 \times 10^{13}$

340

341

342

343

344

345

346

347

348

349

350

351

352

353

354

355

356

357

358

359

360

361

362

363

364

oocysts/district and $1.0 \times 10^{13}$ to $1.2 \times 10^{14} \mathrm{cysts} /$ district, respectively (Fig. 5E and F). Total human emissions were approximately six-fold higher than animal emissions and played a decisive role in total emission distribution. We found slightly more cysts than oocysts in total emissions and human emissions. In contrast, there were slightly more oocysts than cysts in animal emissions. The highest total emissions were found in areas with large animal and human populations, such as the main districts of Wanzhou, Yubei, and Hechuan.

Human Cryptosporidium and Giardia emissions from urban and rural areas can be found in Figure 6. In urban areas, Cryptosporidium and Giardia emissions ranged from $3.5 \times 10^{12}$ to $7.0 \times 10^{13}$ oocysts/district and $5.5 \times 10^{12}$ to $1.1 \times 10^{14}$ cysts/district, respectively (Fig. $6 \mathrm{~A}$ and C). In rural areas, the emissions ranged from 0 to $9.8 \times 10^{12}$ oocysts/district and 0 to $1.6 \times 10^{13}$ cysts/district (Fig. 6B and D). Rural emissions were spread over much larger areas than urban emissions. Human emissions in urban areas were six-fold higher than in rural areas and played a crucial role in total human emission distribution.

\section{Sensitivity analysis}

Since there were limited observational data on Cryptosporidium and Giardia, we performed a sensitivity analysis to verify the GloWPa-TGR-Crypto model's performance. The sensitivity analysis (Tables S6 - S8) showed that the model was the most sensitive to changes in excretion rate (shown for 1 log unit change in excretion rates), particularly the excretion rates of humans (factor 8.03), pigs (factor 2.22), and poultry (factor 1.74). The model was more sensitive to prevalence changes in humans, pigs, and poultry (factors 1.39, 1.14, and 1.08, respectively). The results confirmed that humans, pigs, and poultry were the dominant sources of oocyst and cyst emissions. Besides excretion rate and prevalence, the model was most sensitive to changes in the amount of runoff, STP oocyst and cyst removal efficiencies, the amount of connected emissions, human population, and manure storage time (factors 1.30, 1.23, 1.21, 1.16, and 1.11, respectively), as these parameters affected oocyst and cyst survival and emissions. The model 
365

366

367

368

369

370

371

372

373

374

375

376

377

378

379

380

381

382

383

384

385

386

387

388

389

390

391

392

393

394

395

396

397

398

399

400

401

402

403

404

was not very sensitive to changes in the amount of rural resident feces applied as fertilizer, rural wastewater treatment, and the excretion rates and prevalence of animal species that did not contribute much to the total oocyst and cyst emissions (e.g., cattle, rabbits, sheep, and goats).

\section{Scenario analysis: the effect of population, urbanization, and sanitation changes in $\mathbf{2 0 5 0}$}

In Scenario 1, moderate population change, planned urbanization, and strong improvements in sanitation, wastewater, and manure treatments will decrease the total emissions in the TGR to $9.5 \times 10^{14}$ oocysts/year and $1.2 \times 10^{15}$ cysts/year by 2050 (Fig. 7). This would reduce approximately $40 \%$ of the Cryptosporidium emissions and $44 \%$ of the Giardia emissions measured in 2013. All emissions from all three sources would decrease, with a notable $61 \%$ decrease for rural residents (Table S10). Figure $8 \mathrm{~B}$ and $\mathrm{E}$ and Figure $9 \mathrm{~B}$ and $\mathrm{E}$ show the decrease across all regions in Scenario 1. The largest decline would be found in the Yubei and Jiulongpo districts, where assumed urbanization rates would increase to $100 \%$ and $99 \%$, respectively, and $99 \%$ of domestic sewers would obtain secondary or tertiary treatment. Scenario 1 also shows changes in the contributions to total emissions. Urban residents would be responsible for $64 \%$ and $81 \%$ of Cryptosporidium and Giardia emissions, respectively, which would be a 3\% decrease and a 1\% increase from 2013. Rural Cryptosporidium and Giardia emissions would decrease from $11 \%$ to $7 \%$ and $13 \%$ to $9 \%$, respectively. Livestock Cryptosporidium and Giardia emissions would increase from $22 \%$ to $29 \%$ and $7 \%$ to $10 \%$, respectively.

In Scenario 2, Cryptosporidium and Giardia emissions are expected to increase to $1.9 \times 10^{15}$ oocysts/year and $2.4 \times 10^{15}$ cysts/year by 2050 (Fig. 7), would be $19 \%$ and $12 \%$ growth, respectively, from 2013. Emissions from urban residents and livestock would increase (Table S10) due to strong population growth, unplanned urbanization, limited sanitation, and expanded livestock production practices where untreated manure used as fertilizer is emitted into surface water. Emissions from rural residents would decrease $8 \%$ because the rate of urbanization would increase while the same sanitation practices from 2013 are used by that smaller rural population. Figure $8 \mathrm{C}$ and $\mathrm{F}$ and Figure $9 \mathrm{C}$ and $\mathrm{F}$ show that total emissions would increase in all regions (particularly the Wanzhou and Yubei districts) because of strong population growth and limited environmental regulation. In Scenario 2, urban residents would account for $63 \%$ and $79 \%$, rural residents would account for $9 \%$ and $11 \%$, and livestock would account for $29 \%$ and $10 \%$ of Cryptosporidium and Giardia emissions, respectively, by 2050.

Scenario 3 has the same population, urbanization, and sanitation changes as Scenario 1, but with limited wastewater and manure treatment facilities. Scenario 3 has the highest Cryptosporidium and Giardia emissions of all the scenarios. Total emissions would increase to $2.0 \times 10^{15}$ oocysts/year and $2.7 \times 10^{15}$ cysts/year, with $29 \%$ and $27 \%$ growth compared to 2013 , respectively (Fig. 7). Livestock would see the most growth in emissions (an increase of 42\%) (Table S10). Figure 8D and G and Figure 9D and G show that an increase in emissions across all regions, except in regions with assumed urbanization rates of $100 \%$ and where $50 \%$ of emissions obtain secondary treatment (such as the Yuzhong and Shapingba districts). This result highlights 
405 the importance of wastewater and manure treatment. Connecting populations to sewers without 406 appropriate sewage treatment introduces more waterborne pathogens to surface water, affecting 407 water quality.

408

409

410

\section{Discussion}

411

412

413

414

415

416

417

418

419

420

421

422

423

424

425

426

427

428

429

430

431

432

433

434

435

436

437

438

439

440

441

442

443

The increase in Cryptosporidium and Giardia surface water pollution in China is traced primarily to human and animal feces. China has one of the largest amounts of Cryptosporidium emissions from feces (10 $10^{16}$ oocysts/year; Hofstra et al., 2013; Hofstra \& Vermeulen, 2016; Vermeulen et al., 2019), but Cryptosporidium and Giardia emissions from human and animal feces in surface water across different Chinese provinces or regions have not been closely studied. The TGR, developed by the China Yangtze Three Gorges Project as one of the largest freshwater resources in the world, suffers from Cryptosporidium and Giardia pollution (Xiao et al., 2013ab, Liu et al., 2019). Using data from 2013, we built a GloWPa-TGR-Crypto model to estimate Cryptosporidium spp. and G. duodenalis emissions from human and livestock in the TGR. We also used scenario analyses to predict the effects of sanitation, urbanization, and population changes on oocyst and cyst emissions for 2050. Our study can be used to better understand the risk of water contamination in the TGR and to ensure that the reservoir is adequately protected and treated. This knowledge can also contribute to the implementation of the Water Pollution Control Action Plan (i.e., the Ten-point Water Plan), which was sanctioned by the Chinese government to prevent and control water pollution (Wu et al., 2016). Additionally, our results can serve as an example for other studies on important waterborne pathogens from fecal wastes and wastewater, particularly in developing countries.

Using the GloWPa-TGR-Crypto model, we estimated that the total Cryptosporidium and Giardia emissions from human and livestock feces in Chongqing in 2013 were $1.6 \times 10^{15}$ oocysts/year and $2.1 \times 10^{15}$ cysts/year, respectively. Using the total emissions from the two protozoa, the TGR's hydrological information (such as water temperature, solar radiation, and river depth; Table S11), and the GloWPa-Crypto C1 model (Vermeulen et al., 2019), we preliminarily calculated the mean Cryptosporidium and Giardia concentrations in the TGR in 2013 to be 22 oocysts/10 L and 28 cysts/10 L, respectively. Xiao et al. (2013a) reported that Cryptosporidium oocysts and Giardia cysts are widely distributed in the TGR, with concentrations ranging from 0 to 28.8 oocysts/10 L for Cryptosporidium and 0 to 32.13 cysts/10 L for Giardia in the Yangtze River's mainstream and the backwater areas of tributaries and cities. Liu et al. (2019) used a calibrated hydrological and sediment transport model to investigate the population, livestock, agriculture, and wastewater treatment plants in the Daning River watershed, a small tributary of the TGR in Chongqing, and found Cryptosporidium concentrations of 0.7-33.4 oocysts/10 L. The results from our model were similar to the results found in other studies. Because of the adsorption, deposition, inactivation, and recovery efficiencies of Cryptosporidium and Giardia in water, the oocyst and cyst concentrations in the surface waters of streams and rivers were significantly reduced (Antenucci, Brookes, \& Hipsey,

Peer] reviewing PDF | (2020:02:45998:2:0:NEW 20 Aug 2020) 
444 2005; Searcy et al., 2006; Vermeulen et al., 2019). Therefore, the validity of our model was 445 confirmed.

$446 \quad$ Human and animal feces are main sources of Cryptosporidium and Giardia emissions in 447 surface water. In this study, the majority of human emissions were from densely populated urban

448

449

450

451

452

453

454

455

456

457

458

459

460

461

462

463

464

465

466

467

468

469

470

471

472

473

474

475

476

477

478

479

480

481

482

483 areas (Fig. 6). In those urban areas, a fraction of human emissions were not connected to sewers and sewage was not efficiently treated. We found high concentrations of Cryptosporidium (6.0116.3 oocysts/10 L) and Giardia (59.52-88.21 cysts/10 L) in the effluent from wastewater treatment plants in the TGR area (Xiao et al., 2013ab), and $16.5 \times 10^{8}$ tons of sewage were discharged into the TGR, mainly in urban areas (Xiao et al., 2013a). In rural areas, only $9 \%$ of the population was connected to sewage systems and a large portion of untreated rural sewage was used as potential agricultural irrigation water (Hou, Wang, \& Zhao, 2012). Therefore, we assumed that large amounts of raw sewage were used as a diffuse source that was dumped as a fertilizer after storage into the farmland, where it could then enter tributaries and the mainstream of the Yangtze River via runoff.

We found a lower amount of animal Cryptosporidium and Giardia emissions than human emissions because only $10 \%$ of diffuse emissions reached the TGR through runoff. Unlike the original model created by Hofstra et al. (2013), which estimated livestock oocyst and cyst emissions in surface water, we assumed that a portion of the manure received treatment during storage and before it was applied to soil (An et al., 2017). Recent studies also reported that oocyst emissions on land were associated with mesophilic or thermophilic anaerobic digestion during manure treatment, and could be reduced by several log units (Hutchison et al., 2005; Vermeulen et al., 2017). Additionally, animal emissions are still important. The total global Cryptosporidium spp. emissions from livestock manure are up to $3.2 \times 10^{23}$ oocysts/year (Vermeulen et al., 2017). In 2010, China had a total of 1.9 billion tons of livestock manure, 227 million tons of livestock manure pollution, and 1.84 tons/hectare of arable land of livestock manure pollution (Qiu et al., 2013). Livestock manure discharged into the environment without appropriate processing is a serious source of pollution in soil and water systems (Tian, 2012; An et al., 2017).

Our sensitivity analysis found that the model we used to calculate oocyst and cyst emissions was most sensitive to oocyst and cyst excretion rates, similar to the results from the GloWPaCrypto L1 model (Vermeulen et al., 2017). More detailed information on the toll of cryptosporidiosis and giardiasis and the excretion rates of infected people in Chongqing would improve the model. Additionally, our sensitivity analysis highlighted the significance of runoff. Liu et al. (2019) found that the combined effect of fertilization and runoff played a very important role in oocyst concentration in rivers. Future studies should consider the effect of runoff along with the timing of fertilization. The model was also sensitive to wastewater treatment and manure management. Scenario 3 proposed what would happen if population, urbanization, and sanitation changed similarly to Scenario 1, but without advancements in wastewater treatment and manure management. The results of Scenario 3 indicated that improving urbanization and sanitation with the same population could still result in an increase 
484 in surface water emissions if the sewage and manure management systems are inadequate. The 485 analyses of Scenarios 1 and 2 showed a decrease in oocyst and cyst emissions when there were 486 significant improvements in urbanization, sanitation, wastewater treatment, and manure 487 management, along with appropriate population growth. The effects of population, urbanization, 488 sanitation, manure management, and wastewater treatment on oocysts and cysts should be 489 studied in more detail in order to reduce emissions.

490 Previous studies have used the GloWPa-Crypto model to estimate human and livestock 491 Cryptosporidium emissions across many countries (Hofstra et al., 2013; Hofstra \& Vermeulen, 492 2016; Vermeulen et al., 2017; Vermeulen et al., 2019), but none of these studies included 493 Giardia. In our study, we used the GloWPa-TGR-Crypto model to estimate Cryptosporidium 494 spp. and G. duodenalis emissions from humans and animals in the Chongqing area of the TGR. 495 Unfortunately, the Giardia emissions from rabbits, sheep, and goats were not estimated because 496 there is currently no data for their excretion rates. Earlier studies could not detect Giardia in 497 rabbits, sheep, or goats (Ferguson et al., 2007). Giardia was recently found in sheep and rabbits 498 in northwest and central China, but the cyst excretion rates per $\mathrm{kg}$ of manure were indeterminate 499 (Wang et al., 2016; Jin et al., 2017; Jian et al., 2018; Jiang et al., 2018) and may have been 500 underestimated.

501 To our knowledge, the GloWPa-TGR-Crypto model cannot be validated through the direct 502 comparison of measured surface water values because this method ignores certain factors, such 503 as the infiltration pathways and transport via soils and shallow groundwater to surface water 504 (Bogena et al., 2005; Vermeulen et al., 2017; Watson et al., 2018), the overflow of sewage 505 treatment plants during the flood period (Xiao et al., 2017), traditional dispersive small-scale 506 peasant production ( $L$ i et al., 2016), and the excretion of wildlife (Atwill, Phillips, \& Rulofson, 507 2003). The pathogen loading data of these factors are not readily available. Despite its few 508 shortcomings, we used the GloWPa-TGR-Crypto model to further study environmental pathways, 509 emissions in the TGR, and sources and scenarios for improved management.

510

\section{Conclusions}

512 This study is the first to explore Cryptosporidium spp. and G. duodenalis spatial emissions from 513 human and livestock feces in the TGR, and to identify main sources of this pollution. There was 514 a large amount of total emissions in Chongqing $\left(1.6 \times 10^{15}\right.$ oocysts/year and $2.1 \times 10^{15}$ cysts/year, 515 respectively), indicating the need for effective pollution countermeasures. The total point source 516 emissions from wastewater containing human excretion in urban areas were greater than the total 517 nonpoint source emissions from human and livestock production in rural areas by a factor of 2.0

518 for oocysts and 3.9 for cysts. The emissions from urban areas were mainly from domestic 519 wastewater in densely populated areas, while rural emissions were mainly from livestock feces in 520 concetrated animal production areas. Sewage from cities and livestock feces from rural areas are 521 therefore of particular concern in the TGR area.

522 The GloWPa-TGR-Crypto model was most sensitive to oocyst and cyst excretion rates, 523 followed by prevalence and runoff. If there are significant population, urbanization, and 
524 sanitation management changes by 2050, the total Cryptosporidium and Giardia emissions in the 525 TGR will decrease by $42 \%$ according to Scenario 1, increase by $15 \%$ in Scenario 2 , or increase 526 by $28 \%$ in Scenario 3. Our scenario analyses shows that changes in population, urbanization, 527 sanitation, wastewater management, and manure treatment should be taken into account when 528 trying to improve water quality. The GloWPa-TGR-Crypto model can be further refined by 529 including direct rural resident emissions, direct animal emissions, emissions from sub-surface 530 runoffs, and a more in-depth calculation of concentrations and human health risks using a 531 hydrological model and scenario analysis. Our model can contribute to further understanding of 532 environmental pathways, the risks of Cryptosporidium and Giardia pollution, and the design of 533 effective prevention and control strategies that can reduce the outbreak of waterborne diseases in 534

535

536 the TGR and other similar watersheds.

\section{Acknowledgements}

537

We would like to thank Prof. Jian Wang from Southwest University for their advice and support.

538

539

\section{References}

540

Adeyemo FE, Singh G, Reddy P, Bux F, Stenstro TA. 2019. Efficiency of chlorine and UV in

541

542

543

544

545

546

547

548

549

550

551

552

553

554

555

556

557

558

559

560

561

562 the inactivation of Cryptosporidium and Giardia in wastewater. PLoS One 14: e0216040 DOI: 10.1371/journal.pone.0216040.

An W, Zhang DQ, Xiao S, Yu J, Yang M. 2012. Risk assessment of Giardia in rivers of southern China based on continuous monitoring. Journal of Environmental Sciences 24: 309-313 DOI: CNKI:SUN:HJKB.0.2012-02-020.

An Y, Chen DX, Dong X, Gao SY, Liu WS, Wang LY. 2017. Current situation investigation on non-hazardous treatment of fur animal night soil in northern China. Hei longjiang Animal Science and Veterinary Medicine 29-30 (in Chinese).

Antenucci JP, Brookes JD, Hipsey MR. 2005. A simple model for quantifying Cryptosporidium transport, dilution, and potential in reservoirs. Journal American Water Works Association 97: 86-93 DOI: 10.2307/41312006.

Atwill ER, Phillips R, Rulofson F. 2003. Environmental loading rates of the waterborne pathogenic protozoa, Cryptosporidium parvum, in certain domestic and wildlife species in California. University of California-Davis 47: 1223-1226.

Baldursson S, Karanis P. 2011. Waterborne transmission of protozoan parasites: Review of worldwide outbreaks - An update 2004-2010. Water Research 45: 6603-6614 DOI: 10.1016/j.watres.2011.10.013.

Bartelt LA, Attias E, Black J. 2016. Epidemiology of Cryptosporidiosis and Giardiasis: What pediatricians need to know. Current Tropical Medicine Reports. 3: 108-114 DOI: 10.1007/s40475-016-0081-3.

Bogena H, Kunkel R, Schöbel T, Schrey HP, Wendland F. 2005. Distributed modeling of groundwater recharge at the macroscale. Ecological Modelling 187: 15-26 DOI:

563 10.1016/j.ecolmodel.2005.01.023. 
564

565

566

567

568

569

570

571

572

573

574

575

576

577

578

579

580

581

582

583

584

585

586

587

588

589

590

591

592

593

594

595

596

597

598

599

600

601

602

Carmena D, Aguinagalde X, Zigorraga C, Fernández-Crespo JC, Ocio JA. 2007. Presence of Giardia cysts and Cryptosporidium oocysts in drinking water supplies in northen Spain. Journal of Applied Microbiology 102: 619-629 DOI: 10.1111/j.1365-2672.2006.03193. X.

Castro-Hermida JA, García-Presedo I, Almeida A, González-Warleta M, Da Costa JM, Mezo M. 2009. Detection of Cryptosporidium spp. and Giardia duodenalis in surface water: A health risk for humans and animals. Water Research 43: 4133-4142 DOI: 10.1016/j.watres.2009.06.020.

Castro-Hermida JA, Gonzalez-Warleta M, Mezo M. 2015. Cryptosporidium spp. and Giardia duodenalis as pathogenic contaminants of water in Galicia, Spain: the need for safe drinking water. International Journal of Hygiene and Environmental Health 218: 132-138 DOI: 10.1016/j.ijheh.2014.09.001.

Checkley W, White AC, Jaganath D, Arrowood MJ, Chalmers RM, Chen XM. 2015. A review of the global burden, novel diagnostics, therapeutics, and vaccine targets for Cryptosporidium. Lancet Infectious Diseases 15: 85-94 DOI: 10.1016/S14733099(14)70772-8.

Chen Y, Guo F, Wang J, Cai W, Wang C, Wang K. 2020. Provincial and gridded population projection for China under shared socioeconomic pathways from 2010 to 2100. Scientific Data 7(1):83 DOI: 10.1038/s41597-020-0421-y.

Dixon BR. 2016. Parasitic illnesses associated with the consumption of fresh produce - an emerging issue in developed countries. Current Opinion in Food Science 8: 104-109 DOI: 10.1016/j.cofs.2016.04.009.

Efstratiou A, Ongerth J, Karanis P. 2017a. Evolution of monitoring for Giardia and Cryptosporidium in water. Water Research 123: 96-112 DOI:

10.1016/j.watres.2017.06.042.

Efstratiou A, Ongerth JE, Karanis P. 2017b. Waterborne transmission of protozoan parasites: Review of worldwide outbreaks - An update 2011-2016. Water Research 114: 14-22 DOI: 10.1016/j.watres.2017.01.036.

Ferguson CM, Croke BF, Beatson PJ, Ashbolt NJ, Deere DA. 2007. Development of a process-based model to predict pathogen budgets for the Sydney drinking water catchment. Journal of Water and Health 5: 187-208 DOI: 10.2166/wh.2007.013b.

Fu BJ, Wu BF, Lu YH, Xu ZH, Cao JH, Dong N. 2010. Three Gorges Project: efforts and challenges for the environment. Progress in Physical Geography 34: 741-754 DOI: $10.1177 / 0309133310370286$.

GB18918-2002. 2003. Discharge standard of pollutants for municipal wastewater treatment plant. Standards press of China, Beijing, China (in Chinese).

GB/T5749-2006. 2007. Standards for drinking water quality. Standards press of China, Beijing, China (in Chinese).

GBD 2013 Mortality and Causes of Death Collaborators. 2015. Global, regional, and national age-sex specific all-cause and cause-specific mortality for 240 causes of death, 1990-2013:

Peer) reviewing PDF | (2020:02:45998:2:0:NEW 20 Aug 2020) 
603

604

605

606

607

608

609

610

611

612

613

614

615

616

617

618

619

620

621

622

623

624

625

626

627

628

629

630

631

632

633

634

635

636

637

638

639

640

641

642

a systematic analysis for the Global Burden of Disease Study 2013. Lancet 385(9963):117171 DOI: 10.1016/S0140-6736(14)61682-2.

\section{Ghafari R, Rafiei A, Tavalla M, MoradiChoghakabodi P, Nashibi R, Rafiei R. 2018.} Prevalence of Cryptosporidium species isolated from HIV/AIDS patients in southwest of Iran. Comparative immunology, microbiology and infectious diseases 56: 39-44 DOI: 10.1016/j.cimid.2017.12.002.

Graczyk TK, Fried B. 2007. Human waterborne trematode and protozoan infections. $A d v$ Parasitol. 64: 111-160 DOI: 10.1016/S0065-308X(06)64002-5.

Graczyk TK, Kacprzak M, Neczaj E, Tamang L, Graczyk H, Lucy FE. 2008. Occurrence of Cryptosporidium and Giardia in sewage sludge and solid waste landfill leachate and quantitative comparative analysis of sanitization treatments on pathogen inactivation. Environmental Research 106: 27-33 DOI: 10.1016/j.envres.2007.05.005.

He Q, Peng S, Zhai J, Xiao H. 2011. Development and application of a water pollution emergency response system for the Three Gorges Reservoir in the Yangtze River, China. Journal of Environmental Sciences 23: 595-600 DOI: 10.1016/S1001-0742(10)60424-X.

Hofstra N, Bouwman AF, Beusen AH, Medema GJ. 2013. Exploring global Cryptosporidium emissions to surface water. Science of the Total Environment 442: 10-19 DOI: 10.1016/j.scitotenv.2012.10.013.

Hofstra N, Vermeulen LC. 2016. Impacts of population growth, urbanisation and sanmitation changes on global human Cryptosporidium emissions to surface water. International Journal of Hygiene and Environmental Health 219: 599-605 DOI: 10.1016/j.ijheh.2016.06.005.

Hou HE, Wang ZQ, Zhao FL. 2012. Moderate treatment and resourcing utilization of rural moderate water. Areal Research and Development 31: 119-122 (in Chinese).

Hoxie NJ, Davis JP, Vergeront JM, Nashold RD, Blair KA. 1997. Cryptosporidiosisassociated mortality following a massive waterborne outbreak in Milwaukee, Wisconsin. American journal of public health 87: 2032-2035 DOI: 10.2105/AJPH.87.12.2032.

Huang JL, Qin DH, Jiang T, Wang YJ, Feng ZQ, Zhai JQ. 2019. Effect of fertility policy changes on the population structure and economy of China: from the perspective of the Shared Socioeconomic Pathways. Earth's Future 7(3): 83 DOI: 10.1029/2018EF000964.

Hutchison ML, Walters LD, Moore A, Avery SM. 2005. Decline of zoonotic agents in liquid livestock wastes stored in batches on-farm. Journal of Applied Microbiology 99: 58-65 DOI: $10.1111 /$ j.1365-2672.2005.02585. X.

Iqbal M S, Islam MMM, Hofstra N. 2019. The impact of socio-economic development and climate change on E. coli loads and concentrations in Kabul River, Pakistan. Science of the Total Environment 650: 1935-1943 DOI: 10.1016/j.scitotenv.2018.09.347.

Jian Y, Zhang X, Li X, Karanis G, Ma L, Karanis P. 2018. Prevalence and molecular characterization of Giardia duodenalis in cattle and sheep from the Qinghai-Tibetan Plateau Area (QTPA), northwestern China. Veterinary parasitology 250: 40-44 DOI: 10.1016/j.vetpar.2017.12.001. 
643 Jiang L, O'Neill BC. 2017. Global urbanisation projections for the shared socioeconomic

644

645

646

647

648

649

650

651

652

653

654

655

656

657

658

659

660

661

662

663

664

665

666

667

668

669

670

671

672

673

674

675

676

677

678

679

680

pathways. Global Environmental Change 42: 193-199 DOI:

10.1016/j.gloenvcha.2015.03.008.

Jiang J, Ma JG, Zhang NZ, Xu P, Hou G, Zhao Q. 2018. Prevalence and risk factors of Giardia duodenalis in domestic rabbbits (Oryctolagus cuniculus) in Jilin and Liaoning province, northeastern China. J. Infect. Public. Health 11(5): 723-726 DOI: 10.1016/j.jiph.2018.02.008.

Jin Y, Fei J, Cai, J, Wang X, Li N, Guo Y. 2017. Multilocus genotyping of Giardia duodenalis in Tibetan sheep and yaks in Qinghai, China. Veterinary parasitology 247: 70-76 DOI: 10.1016/j.vetpar.2017.09.021.

Kiulia NM, Hofstra N, Vermeulen LC, Obara MA, Medema G, Rose JB. 2015. Global occurrence and emission of Rotaviruses to surface waters. Pathogens 4: 229-255 DOI: 10.3390/pathogens4020229.

Li WW, Xue LG, Mo TL, Li GQ, Yang RQ. 2016. Research progress on the technological study of domestic sewage treatment in rural area by biological method. Guangzhou Chemical Industry and Technology 44: 5-8 (in Chinese).

Li X, Chase JA, Bond RF, Lor P, Fernandez K, Partyka ML. 2019. Microbiological safety of popular recreation swimming sites in Central California. Environmental Monitoring and Assessment 191: 456-467 DOI: 10.1007/s10661-019-7601-2.

Li Y, Huang S, Qu X. 2017. Water pollution prediction in the Three Gorges Reservoir area and countermeasures for sustainable development of the water environment. International Journal of Envornmental Research and Public Health 14: 1307-1325 DOI: 10.3390/ijerph14111307.

Liu A, Gong B, Liu X, Shen YJ, Wu YC, Zhang WZ. 2020. A retrospective epidemiological analysis of human Cryptosporidium infection in China during the past three decades (19872018). PLoS Neglected Tropical Diseases 14(3): e0008146 DOI: 10.1371/journal.pntd.0008146.

Liu J, Platts-Mills JA, Juma J, Kabir F, Nkeze J, Okoi C. 2016. Use of quantitative molecular diagnostic methods to identify causes of diarrhoea in children: a reanalysis of the GEMS case-control study. Lancet 388: 1291-1301 DOI: 10.1016/S0140-6736(16)31529-X.

Liu W, An W, Jeppesen E, Ma J, Yang M, Trolle D. 2019. Modelling the fate and transport of Cryptosporidium, a zoonotic and waterborne pathogen, in the Daning River watershed of the Three Gorges Reservoir Region, China. Journal of Environmental Management 232: 462-474 DOI: 10.1016/j.jenvman.2018.10.064.

Martins FDC, Ladeia WA, Toledo RDS, Garcia JL, Navarro IT, Freir RL. 2019. Surveillance of Giardia and Cryptosporidium in sewage from an urban area in Brazil. Brazilian Journal of Veterinary Parasitology 28: 291-297 DOI: 10.1590/S198429612019037.

Peer] reviewing PDF | (2020:02:45998:2:0:NEW 20 Aug 2020) 
681

682

683

684

685

686

687

688

689

690

691

692

693

694

695

696

697

698

699

700

701

702

703

704

705

706

707

708

709

710

711

712

713

714

715

716

717

718

719

Mons C, Dumètre A, Gosselin S, Galliot C, Moulin L. 2008. Monitoring of Cryptosporidium and Giardia river contamination in Paris area. Water Research 43: 211-217 DOI: 10.1016/j.watres.2008.10.024.

Norhayati M, Fatmah MS, Yusof S, Edariah AB. 2003. Intestinal parasitic infections in man: a review. Med. J. Malaysia 58(2): 296-305.

O'Neill BC, Kriegler E, Ebi KL, Kemp-Benedict E, Riahi K, Rothman DS. 2015. The roads ahead: narratives for shared socioeconomic pathways describing world futures in the $21 \mathrm{st}$ century. Global Environmental Change 42: 169-180 DOI: 10.1016/j.gloenvcha.2015.01.004.

Qiu HG, Liao SP, Jing Y, Luan J. 2013. Regional differences and development tendency of livestock manure pollution in China. Chinese Journal of Environmental Science 34: 27662774 DOI: 10.13227/j.hjkx.2013.07.010.

Quihui-Cota L, Morales-Figueroa GG, Javalera-Duarte A, Ponce-Martínez JA, ValbuenaGregorio E, López-Mata MA. 2017. Prevalence and associated risk factors for Giardia and Cryptosporidium infections among children of northwest Mexico: a cross-sectional study. BMC Public Health 17: 852-861 DOI: 10.1186/s12889-017-4822-6.

Ryan U, Fayer R, Xiao L. 2014. Cryptosporidium species in humans and animals: current understanding and research needs. Parasitology 141: 1667-1685 DOI: 10.1017/S0031182014001085.

Saaed FMA, Ongerth JE. 2019. Giardia and Cryptosporidium in children with diarrhea, Kufra, Libya, a North African migration route city. International Journal of Envornmental Research and Public Health 222: 840-846 DOI: 10.1016/j.ijheh.2019.04.006.

Sahraoui L, Thomas M, Chevillot A, Mammeri M, Polack B, Vallée I, Follet J, Ain-Baaziz H, Adjou KT. 2019. Molecular characterization of zoonotic Cryptosporidium spp. and Giardia duodenalis pathogens in Algerian sheep. Veterinary Parasitology: Regional Studies and Reports 16: 100280 DOI: 10.1016/j.vprsr.2019.100280.

Sang C, Zheng Y, Zhou Q, Li D, Liang G, Gao Y. 2019. Effects of water impoundment and water-level manipulation on the bioaccumulation pattern, trophic transfer and health risk of heavy metals in the food web of Three Gorges Reservoir (China). Chemosphere 232: 403414 DOI: 10.1016/j.chemosphere.2019.04.216.

Searcy KE, Packman AI, Atwill ER, Harter T. 2006. Deposition of Cryptosporidium oocysts in streambeds. Applied and environmental microbiology 72: 1810-1816 DOI: 10.1128/AEM.72.3.1810-1816.2006.

Šlapeta J. 2013. Cryptosporidiosis and Cryptosporidium species in animals and humans: A thirty colour rainbow. International Journal for Parasitology 43: 957-970 DOI: 10.1016/j.ijpara.2013.07.005.

Tang J, McDonald S, Peng X, Samadder SR, Murphy TM, Holden NM. 2011. Modelling Cryptosporidium oocysts transport in small ungauged agricultural catchments. Water Research 45(12):3665-3680 DOI: 10.1016/j.watres.2011.04.013. 
720

721

722

723

724

725

726

727

728

729

730

731

732

733

734

735

736

737

738

739

740

741

742

743

744

745

746

747

748

749

750

751

752

753

754

755

756

757

Tangtrongsup S, Sripakdee D, Malaivijitnond S, Angkuratipakorn R, Lappin M. 2019. Intestinal parasites and the occurrence of zoonotic Giardia duodenalis genotype in captive gibbons at Krabokkoo wildlife breeding center, Thailand. Trends in Parasitology 33: 561576 DOI: $10.3389 /$ fvets.2019.00110.

Tian YS. 2012. Potential assessment on biogas production by using livestock manure of largescale farm in China. Transactions of the Chinese Society of Agricultural Engineering 28: 230-234 DOI: 10.3969/j.issn.1002-6819.2012.08.036.

Velthof GL, Oudendag D, Witzke HP, Asman WA, Klimont Z, Oenema O. 2009. Integrated assessment of nitrogen losses from agriculture in EU-27 using MITERRA-EUROPE. Journal of environmental quality 38(2):402-417 DOI: 10.2134/jeq2008.0108.

Vermeulen LC, Benders J, Medema G, Hofstra N. 2017. Global Cryptosporidium loads from livestock manure. environmental science and technology 51: 8663-8671 DOI: 10.1021/acs.est.7b00452.

Vermeulen LC, Kraker JD, Hofstra N, Kroeze C, Medema G. 2015. Modelling the impact of sanitation, population growth and urbanization on human emissions of Cryptosporidium to surface waters - a case study for Bangladesh and India. Environmental Research Letters 10: 094017 DOI: 10.1088/1748-9326/10/9/094017.

Vermeulen LC, van Hengel M. Kroeze C, Medema G, Spanier JE, van Vliet MTH. 2019. Cryptosporidium concentrations in rivers worldwide. Water Research 149: 202-214 DOI: 10.1016/j.watres.2018.10.069.

Wang HY, Qi M, Zhang K, Li J, Huang J, Ning C, Zhang LX. 2016. Prevalence and genotyping of Giardia duodenalis isolated from sheep in Henan Province, central China. Infection, genetics and evolution: journal of molecular epidemiology and evolutionary genetics in infectious diseases 39: 330-335 DOI: 10.1016/j.meegid.2016.02.006.

Watson A, Miller J, Fleischer M, Clercq WD. 2018. Estimation of groundwater recharge via percolation outputs from a rainfall/runoff model for the Verlorenvlei estuarine system, west coast, South Africa. Journal of Hydrology 558: 238-254 DOI:

10.1016/j.jhydrol.2018.01.028.

WHO. The global burden of disease: 2004 update. Geneva: WHO (World Health Organisation); 2008.

Wu G, Miao Z, Shuai S, Jiang KS, Geng Y, Li DJ. 2016. Evaluating the construction efficiencies of urban wastewater transportation and treatment capacity: Evidence from 70 megacities in China. Resources, Conservation and Recycling 128: 373-381 DOI: 10.1016/j.resconrec.2016.08.020.

Wu Y, Chang Y, Chen Y, Zhang X, Li D, Zheng S, Wang L, Li JQ, Ning CS, Zhang LG. 2018. Occurrence and molecular characterization of Cryptosporidium spp., Giardia duodenalis, and Enterocytozoon bieneusi from Tibetan sheep in Gansu, China. Infection, Genetics and Evolution 64: 46-51 DOI: 10.1016/j.meegid.2018.06.012. 
758

759

760

761

762

763

764

765

766

767

768

769

770

771

772

773

774

775

776

777

778

779

780

781

782

783

784

785

Xiao G, Qiu Z, Qi J, Chen J, Liu F, Liu W, Luo JH, Shu WQ. 2013a. Occurrence and potential health risk of Cryptosporidium and Giardia in the Three Gorges Reservoir, China. Water Research 47: 2431-2445 DOI: 10.1016/j.watres.2013.02.019.

Xiao G, Wang Z, Chen J, Qiu Z, Li Y, Qi J, Liu WY, Shu WQ. 2013b. Occurrence and infection risk of waterborne pathogens in Wanzhou watershed of the Three Gorges Reservoir, China. Journal of Environmental Sciences 25: 1913-1924 DOI: CNKI: SUN: HJKB.0.2013-09-025.

Xiao L, Fayer R. 2008. Molecular characterisation of species and genotypes of Cryptosporidium and Giardia and assessment of zoonotic transmission. International Journal for Parasitology 38: 1239-1255 DOI: 10.1016/j.ijpara.2008.03.006.

Xiao S, Hu S, Zhang Y, Zhao X, Pan W. 2017. Influence of sewage treatment plant effluent discharge into multipurpose river on its water quality: A quantitative health risk assessment of Cryptosporidium and Giardia. Environmental pollution 233: 797-805 DOI: 10.1016/j.envpol.2017.11.010.

Yang YL, Shen LJ, Xie DT, Luo YZ, Ni JP. 2015. Estimation of pollution loads from agricultural nonpoint sources in Three Gorges Reservoir Area (Chongqing) based on the export coefficient modeling approach. Journal of Southwest University (Natural Science) 37: 112-119, DOI: 10.13718/j.cnki.xdzk.2015.03.019.

Yang ZY, Cao JP, Shen YJ, Liu AQ. 2017. Epidemiology status of some new emerging Cryptosporidium species and genotypes in humans. Chinese Jurnal of Zonoses 33: 148-155 DOI: 10.3969/j.issn.1002-2694.2017.02.011.

Zhang JC, Hu RG, Lei MG, Liu J, Gao X, Qi DS. 2017. Research progress on innocuous treatment technique of livestock and poultry manure. Acta Ecologae Animalis Domastici 38: 85-90 (in Chinese).

Zhao J. 2018. Study on the changes of national population and economy based on the grid under the Shared Socioeconomic Pathways by IPCC. Thesis, Nanjing University of Information Science \&Technology (in Chinese).

Peer) reviewing PDF | (2020:02:45998:2:0:NEW 20 Aug 2020) 
Figure 1

Maps of population (A), livestock density (B) and river system of the Three Gorges Reservoir in Chongqing.

The data was derived from Chongqing Statistic Bureau, China (http://tjj.cq.gov.cn/). 


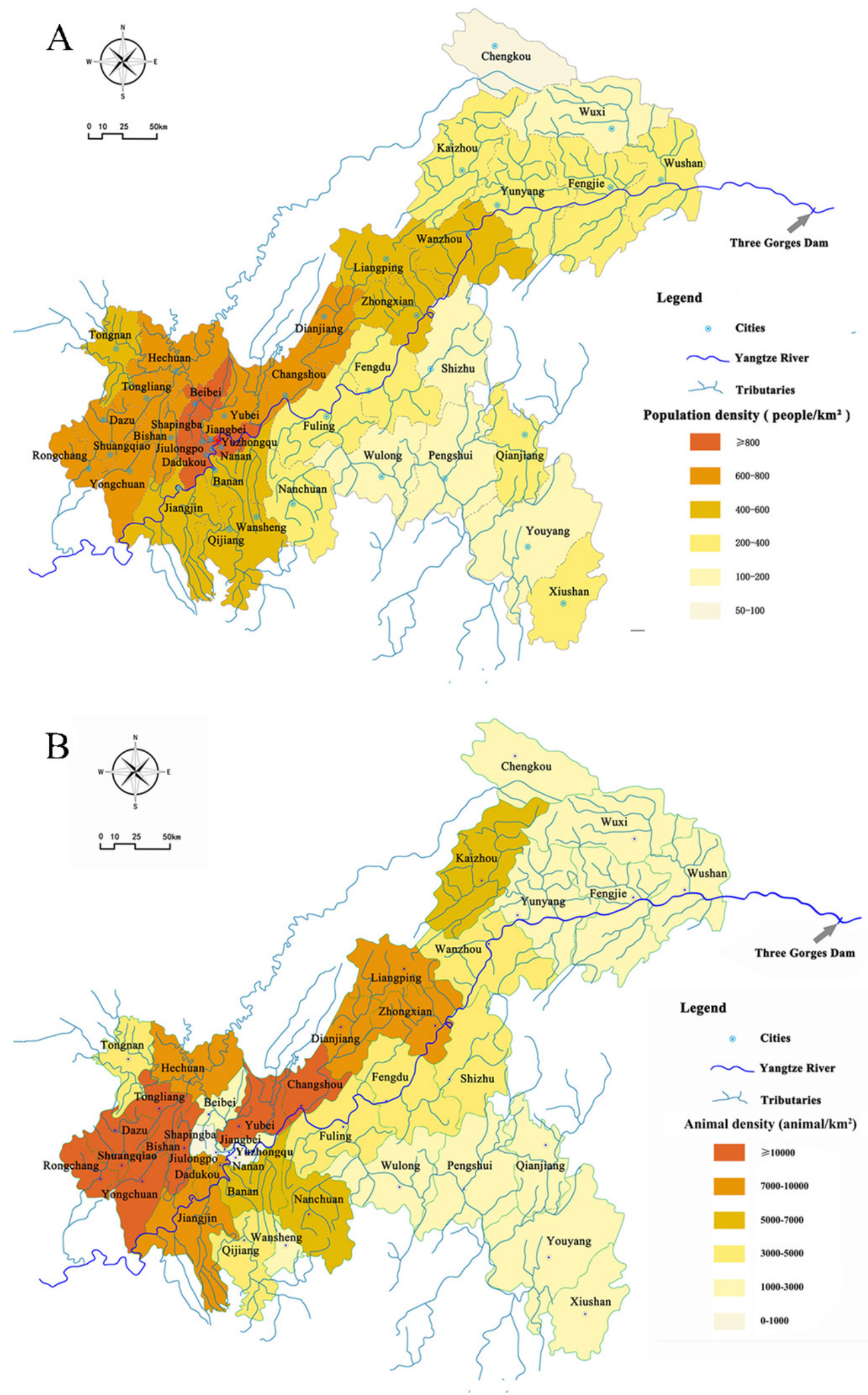




\section{Figure 2}

Schematic sketch of the model's components of the GloWPa-Crypto TGR adapted from Hofstra et al. (2013).

Gray boxes are the major model subcomponents that are calculated, arrows give the pathway of Cryptosporidium and Giardia. Point sources are human emissions ( $H$ is total human emissions, $N_{p}$ is the human population, $O_{p}$ is the human average oocyst and cyst excretion rates) via sewage systems ( $F_{\text {rem }}$ is the fraction of oocysts and cysts removed by the STP) or direct discharge into the TGR. Nonpoint sources are emissions from rural residents (without connected STP) or animals ( $A$ is total animal emissions, $N_{a}$ is the number of animals, $O_{a}$ is the average oocyst and cyst excretion rates per animal) resulting from manure being used as fertilizer after storage and entering surface water via runoff. The oocyst and cyst emission to the TGR $(E)$ is the main model output. Grey arrows may be important but are not taken into account in the model. 


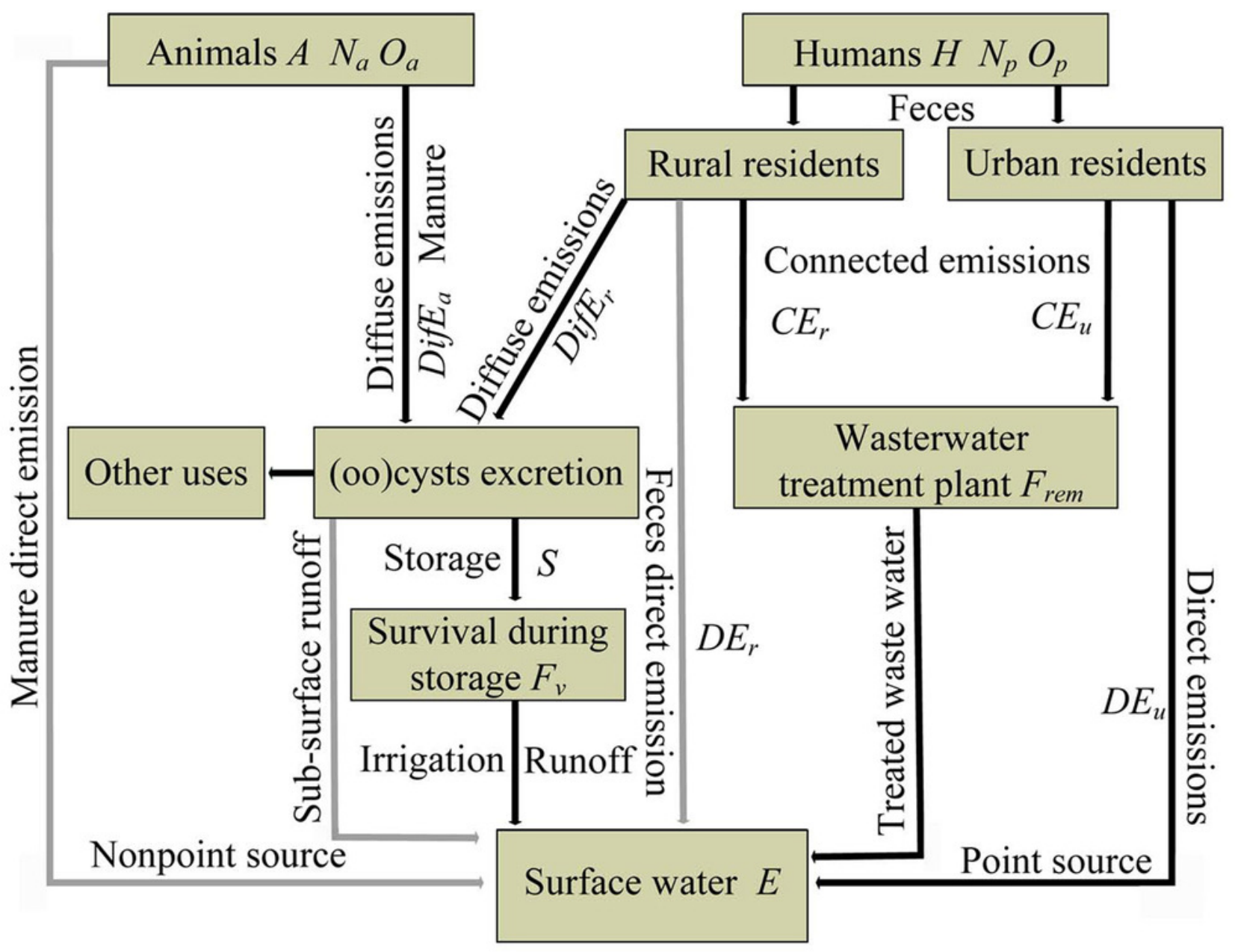


Figure 3

Total Cryptosporidium oocyst and Giardia cyst emissions in the TGR for Chongqing in 2013.

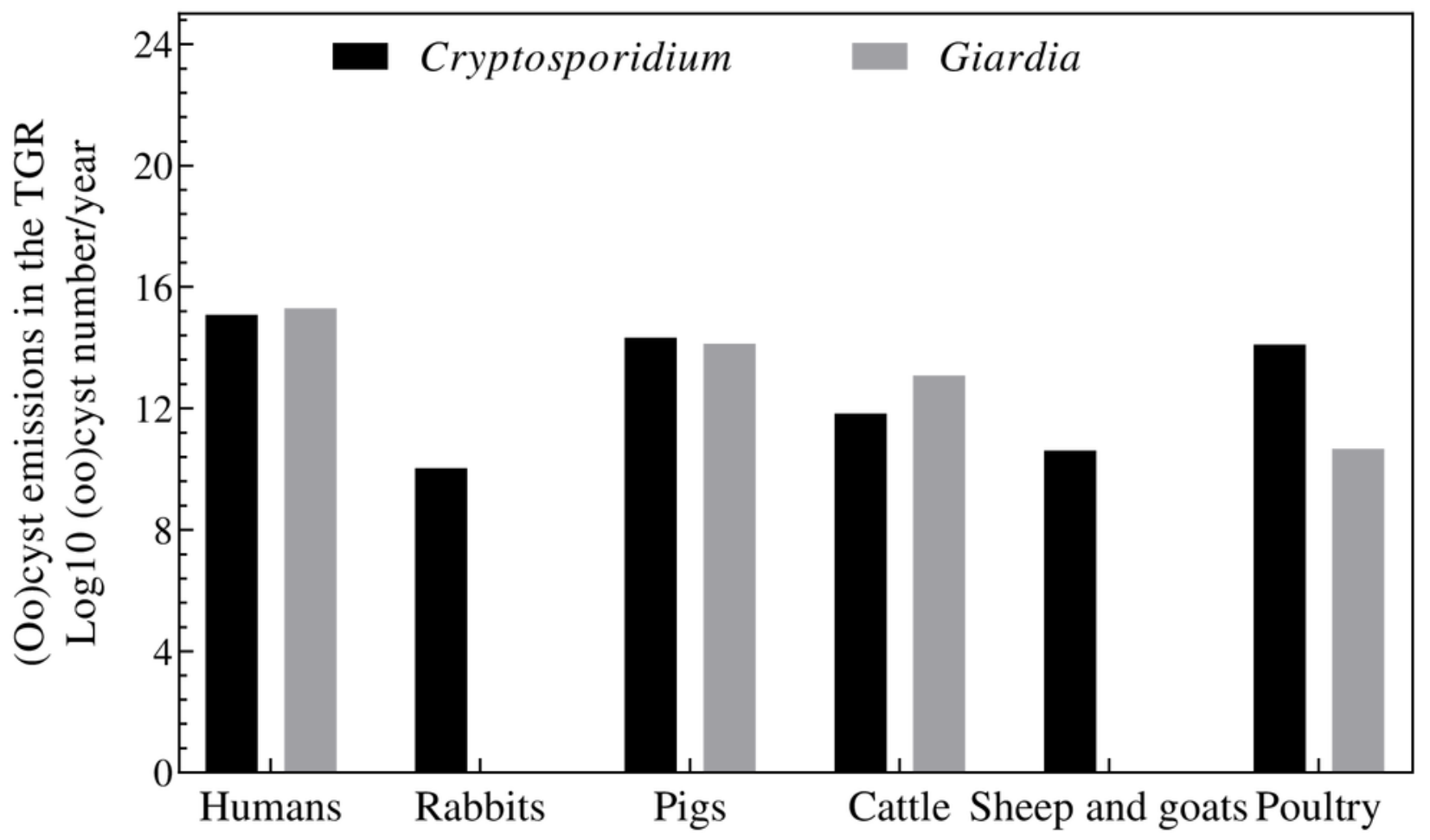




\section{Figure 4}

Fraction (\%) of four oocyst and cyst emission categories caused by the population in the model.

Fraction (\%) of four oocyst and cyst emission categories caused by the population in the model. Four emission categories are used in our model: (1) connected emissions (the fraction of humans connecting to sewage systems or livestock receiving manure treatment), (2) direct emissions (the fraction of urban residents not connecting to sewage systems), (3) diffuse emissions (the fraction of rural residents or livestock resulting from manure being used as fertilizer after storage and entering surface water via runoff) and (4) non-source (the fraction of oocysts and cysts are not emissions to the environment ).

\section{Non-source Diffuse Direct $\square$ Connected}

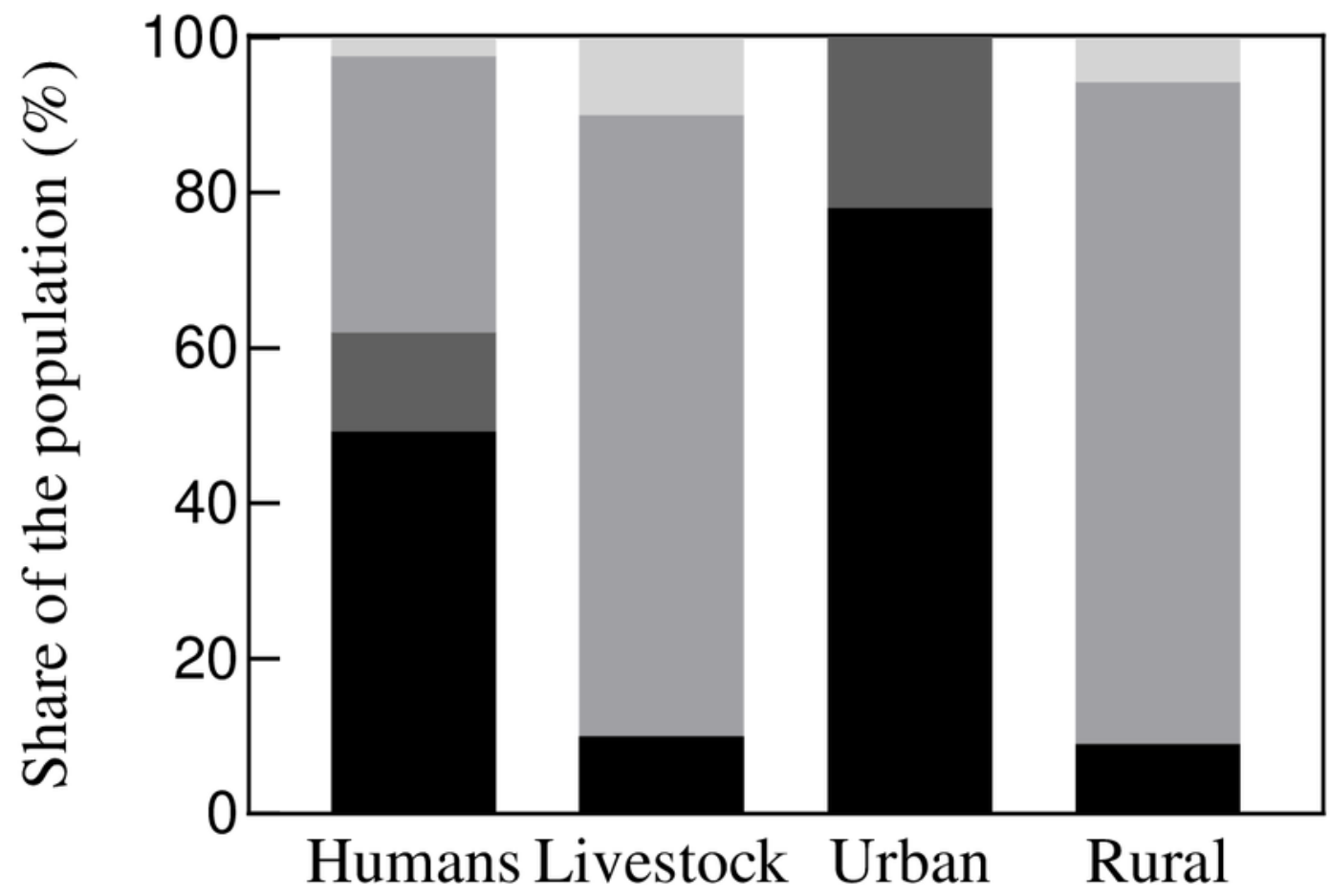


Figure 5

Cryptosporidium oocyst and Giardia cyst emissions in the TGR for each Chongqing district or county from 2013.

A) human oocyst emissions, B) human cyst emissions, C) animal oocyst emissions, D) animal cyst emissions, E) total Cryptosporidium oocyst emissions, F) total Giardia cyst emissions. 

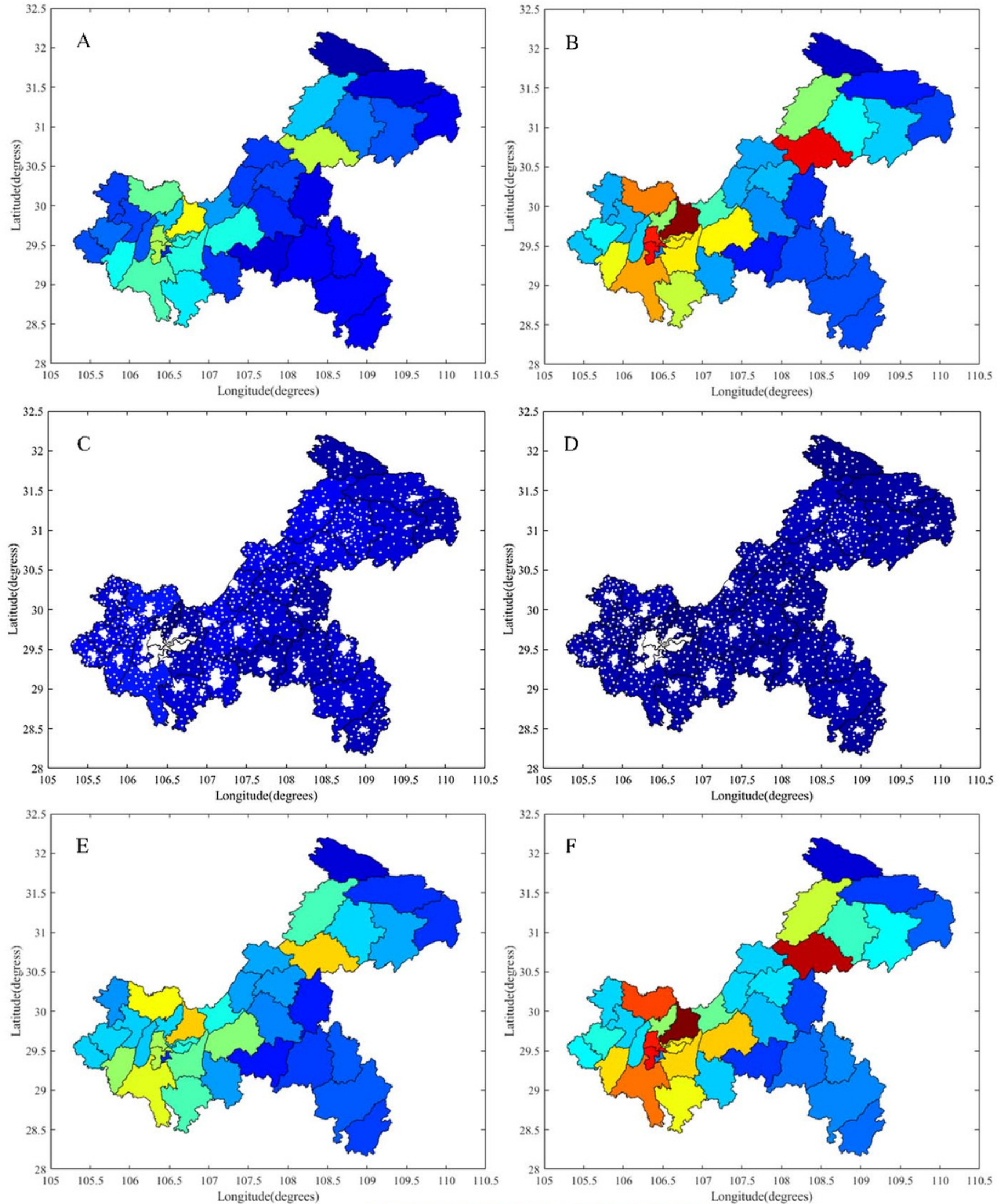

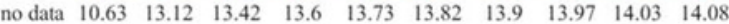

Log10 (oo)cysts/grid/year 
Figure 6

Human emissions of Cryptosporidium oocysts and Giardia cysts in urban and rural areas for each Chongqing district or county from 2013.

A) urban oocyst, B) rural oocyst, C) urban cyst and D) rural cyst.
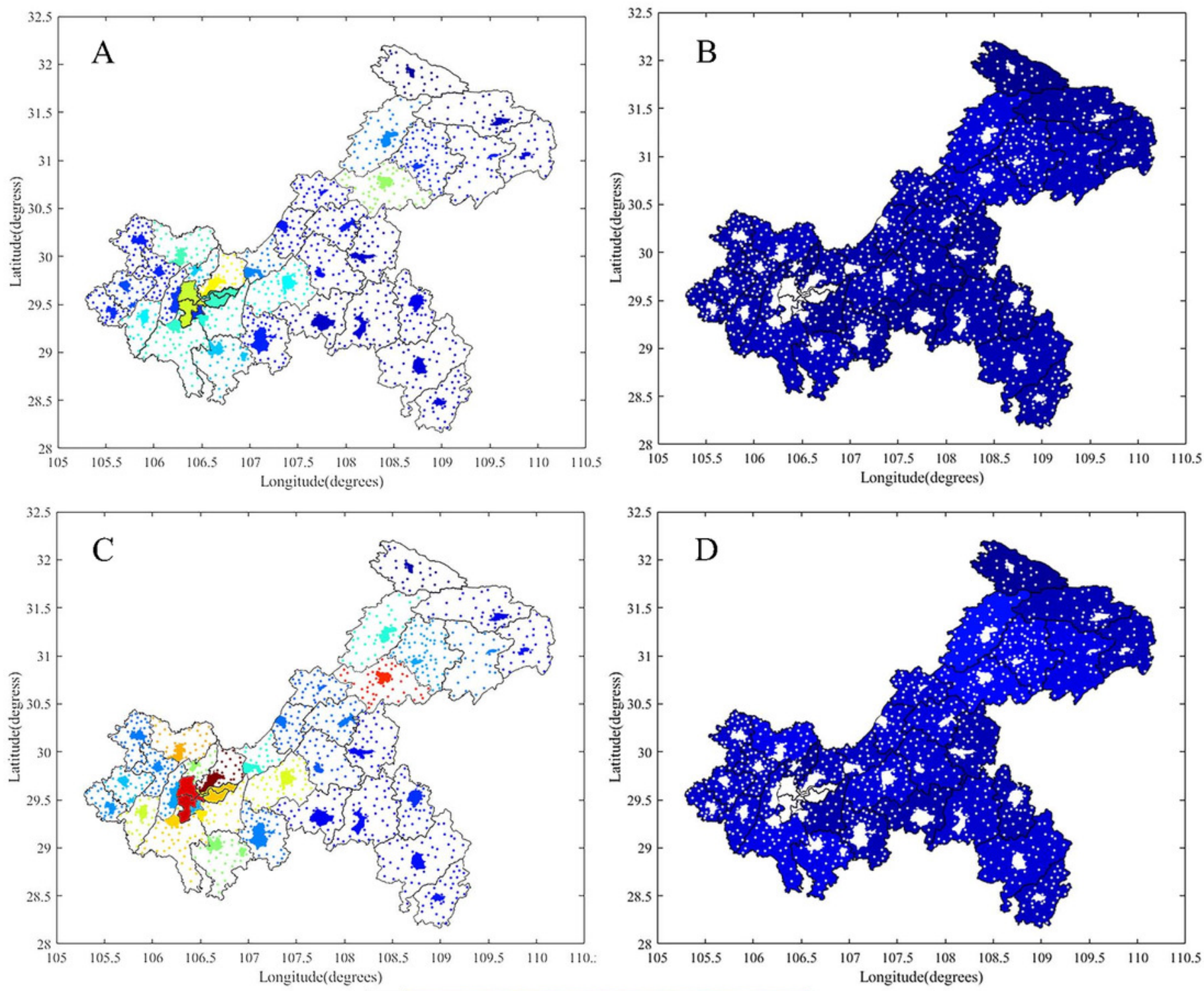

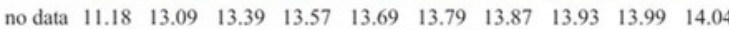

Log10 (oo)cysts/grid/year 


\section{Figure 7}

Total Cryptosporidium oocysts and Giardia cysts emissions from urban residents, rural residents and livestock in the Chongqing area of the TGR in 2013 and for 2050 based on three scenarios.

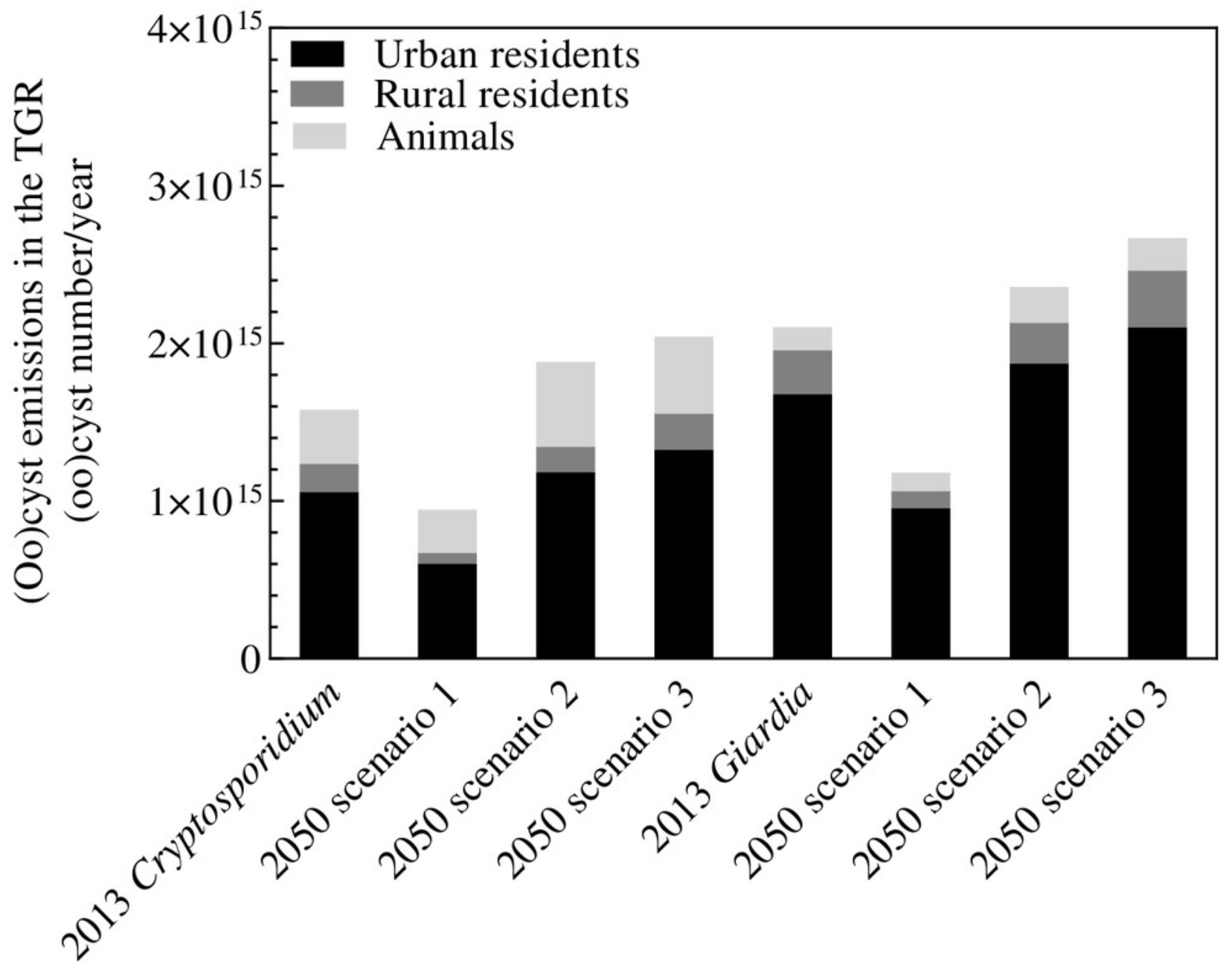


Figure 8

Differences of Cryptosporidium emissions between 2013 and 2050 for each Chongqing district or county based three scenarios.

Emissions in 2013 (A), emissions of scenario 1 (B), scenario 2 (C), and scenario 3 (D) for 2050, and emission differences between 2050 and 2013 for scenario 1 (E), scenario 2 (F), and scenario $3(\mathrm{G})$. 

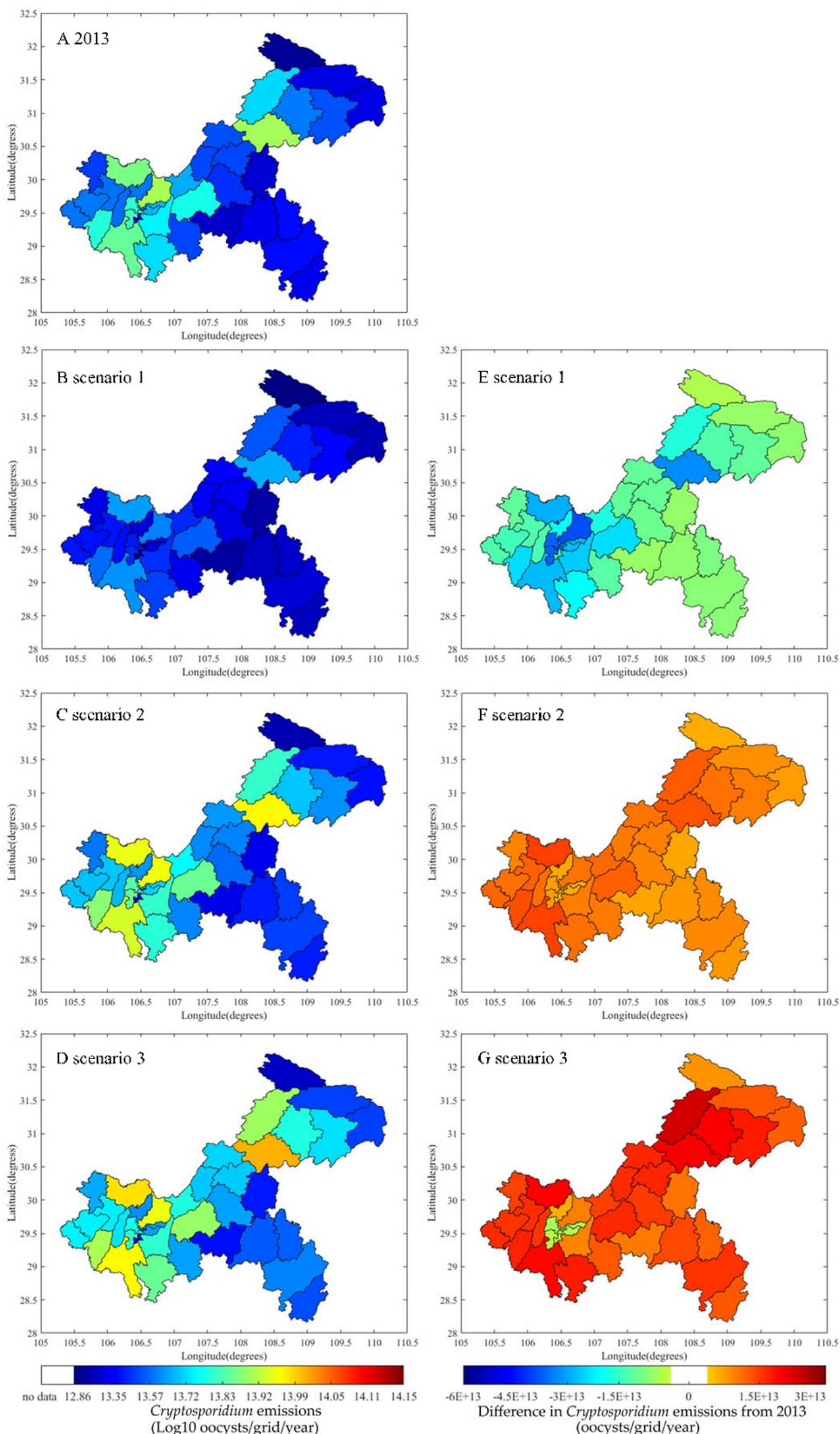

PeerJ reviewing PDF | (2020:02:45998:2:0:NEW 20 Aug 2020) 
Figure 9

Differences of Giardia emissions between 2013 and 2050 for each Chongqing district or county based three scenarios.

Emissions in 2013 (A), emissions of scenario 1 (B), scenario 2 (C), and scenario 3 (D) for 2050, and emission differences between 2050 and 2013 for scenario 1 (E), scenario 2 (F), and scenario $3(G)$. 

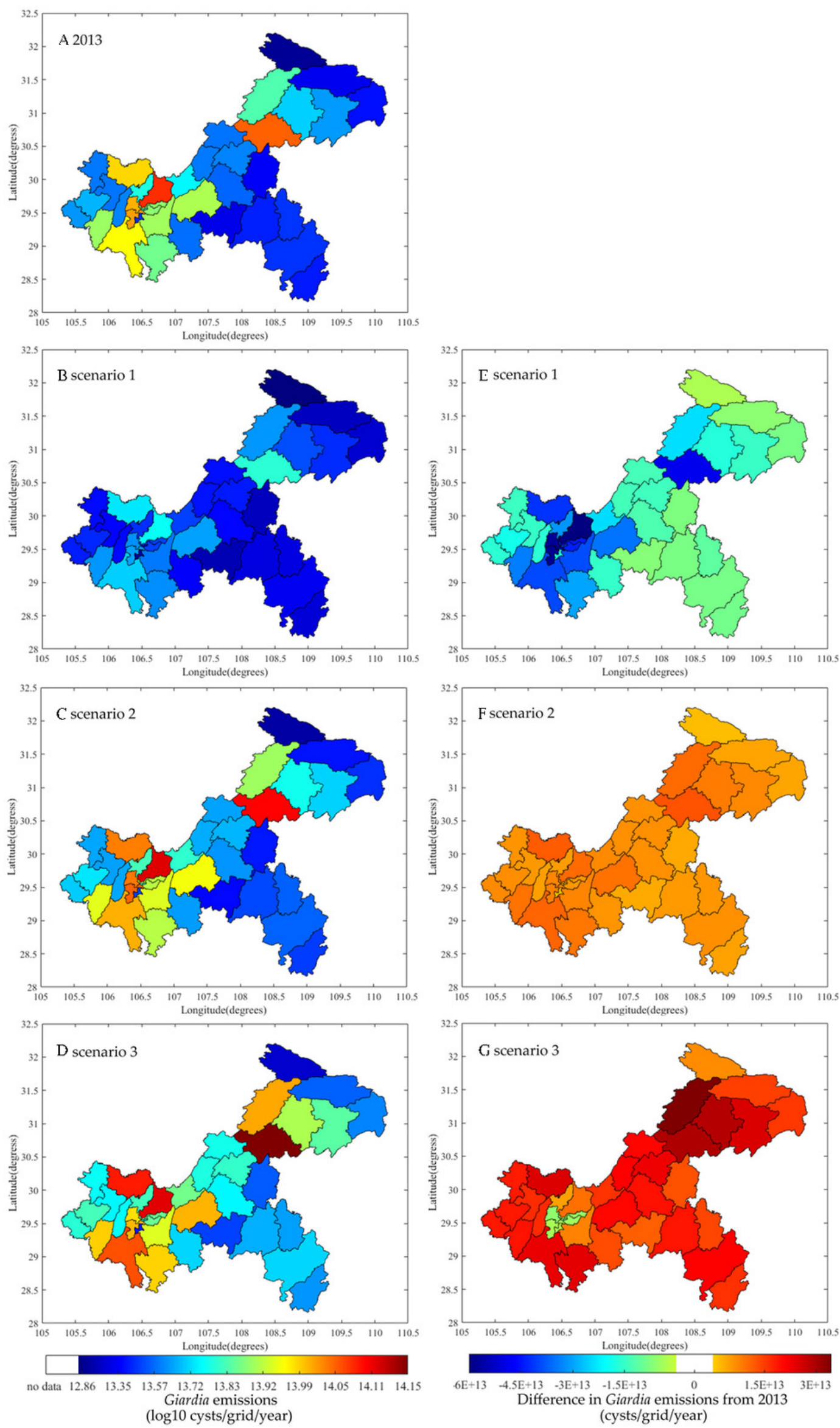

Peer) reviewing PDF | (2020:02:45998:2:0:NEW 20 Aug 2020) 